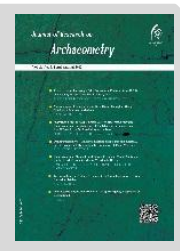

\title{
Climatic Hazards of Fourth Millennium BC and Cultural Responses of Human Societies Case Study: Tehran Plain and Qomroud-Gharachay Basin
}

\author{
Ahmad Chaychi Amirkhiz ${ }^{1 *}$, Babak Shaikh Baikloo Islam² \\ ${ }_{1}$ Archaeological Research Center, Research Institute of Cultural heritage and Tourism, Tehran, IRAN \\ ${ }^{2}$ Department of History and Archaeology, Science and Research Branch, Islamic Azad University, Tehran, IRAN
}

Received: 02/12/2019

Accepted: 28/06/2020

\begin{abstract}
Climatic conditions have dried up since the late 5th millennium BC as if Paleoclimate research in the northern hemisphere, particularly Iran and neighboring countries, shows unfavorable climatic conditions and several periods of severe drought during 4th millennium BC. Also, based on environmental sedimentological studies on archaeological sites such as Mafin Abad of Islamshahr and Meymanat Abad of Robat Karim in Tehran province and Ghara Tepe of Qomroud in Qom province, it has been determined that all three sites were flooded by neighboring rivers in the mid and late 4th millennium BC. The occurrence of these floods coincided with the severe droughts in the 4th millennium BC. The enormous floods caused by severe centralized rains are, in principle, one of the main features of climate change and droughts. As the drought intensified, especially since the late-4th millennium BC, human populations in the cultural region of North Central Iran have decreased, leading to a cultural decline during the Bronze Age. This research tries to study the destructive impacts of climate change on ancient societies of the Tehran plain and the Qomroud-Gharachay basin, located in the western part of the North Central region of Iran. For this purpose, paleoclimate research of the Holocene Age and environmental sedimentological studies of ancient sites contemporary with Sialk III period have been used. Also, during environmental surveys of the Mafin Abad site, evidence of an ancient stream (possibly one of the branches of the Karaj River) belonging to the mid-4th millennium BC, was discovered. It is probable that the uprising of the same river destroyed the ancient village. The XRD analysis on the sediments of this river indicates the deliberate selection of this location for establishment of the important settlement in 5th and 4th millennium BC. According to the sedimentology, the ancient stream has been one of the most valuable mine of pottery clay in the whole of North Central Iran. Previously, there was one of the largest ceramic factories near Mafin Abad, which uses peripheral soil. Also, the existence of very fine and excellent pottery of Mafin Abad, belonging to the Cheshmeh Ali Culture with 3mm thickness is another reason to support this hypothesis. Thus, Mafin Abad has great environmental potential for attracting human communities, but has failed to reach the threshold of urbanization. Mafin Abad and Ghara Tepe in the mid-4th millennium BC and Meymant Abad in the late-4th millennium BC ended their lives. Although it is not yet known exactly where the Meymanat Abad settlement was formed after the Mafin Abad collapse, but because the most recent Mafin Abad cultural material belongs to the early Sialk III phase and the oldest Meymanat Abad cultural material belongs to the same period, it is likely that after the end of Mafin Abad due to the flooding of the ancient stream which was a branch of the Karaj River, Meymanat Abad has been established. Since the absolute dating of Meymanat Abad indicates the oldest settlement at around $3700 \mathrm{BC}$, it may be possible to attribute this date time to the flood in Mafin Abad. As noted, most of the paleoclimate researches confirm the occurrence of a climate change and drought in about 3700-3500 BC. Also, the eventual collapse of Meymanat Abad in
\end{abstract}

\footnotetext{
* Corresponding author: a.chaychi@richt.ir
}

Copyright(C) 2020, the Authors / This open-access article is published under the terms of the Creative Commons Attribution-NonCommercial 4.0 International License which permits Share (copy and redistribute the material in any - medium or format) and Adapt (remix, transform, and build upon the material) under the Attribution

NonCommercial terms. 
the late 4th millennium BC overlaps with the $5.2 \mathrm{ka} \mathrm{BP}$ drought event (3200 BC) that continued until the early 3rd millennium BC. Since then, the long cultural decline began in the North Central Iran region and covered the whole Bronze Age. Perhaps one of the most important reasons for the significant decreased of settlements and the existence of only one to two layers of settlement after the Sialk III period was severe climate change. These natural hazards have undoubtedly had profound impacts on the subsistence system of the North Central societies of Iran.

Keywords: Dry event, 4th millennium BC, Tehran plain, Qomroud-Gharachay basin, Paleoclimate Research, XRD analysis 


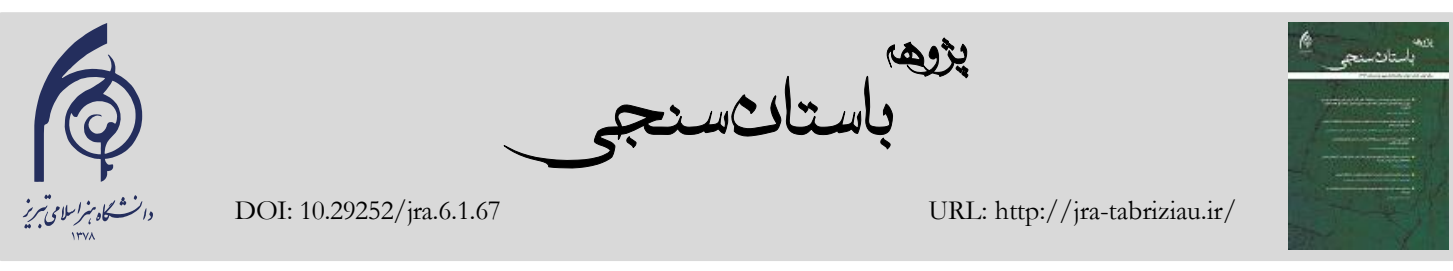

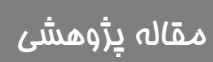

\section{$\bigodot_{\text {CrossMark }}$

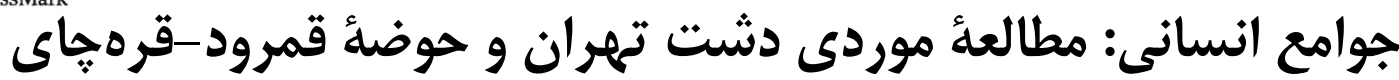

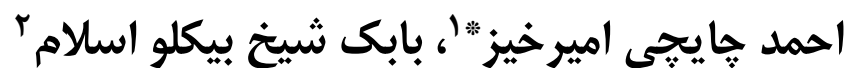

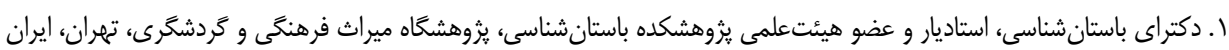

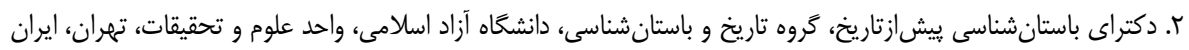

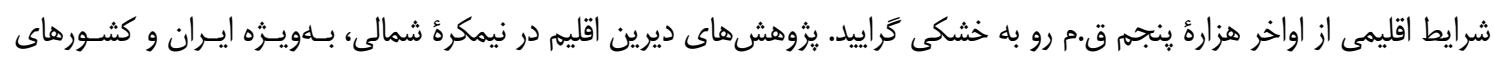

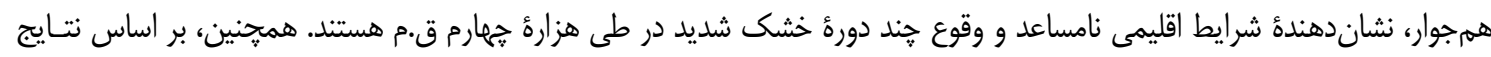

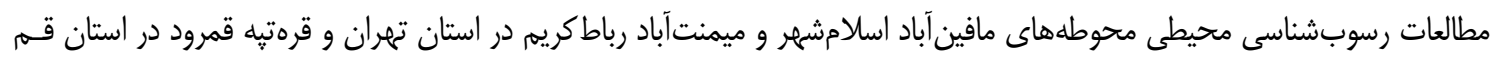

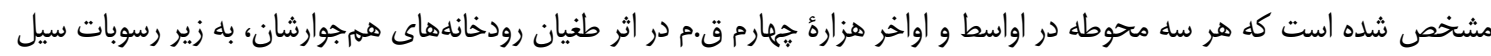

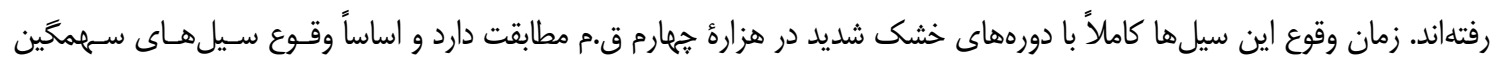

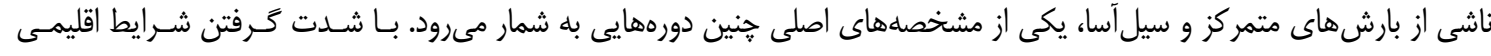

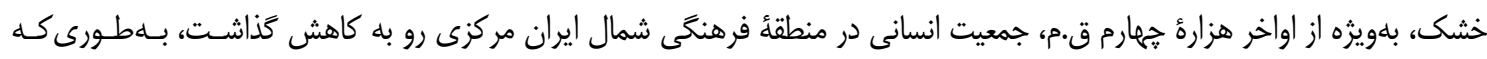

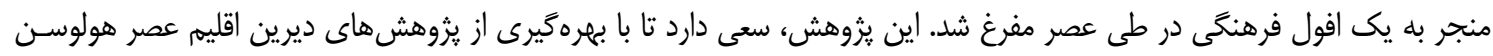

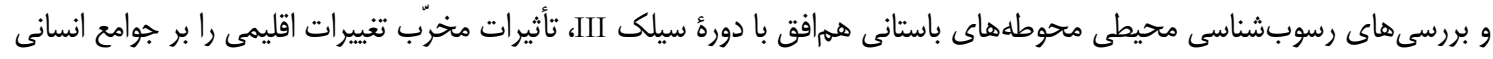

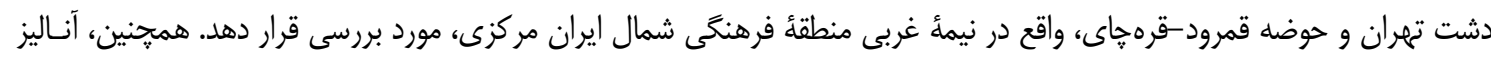

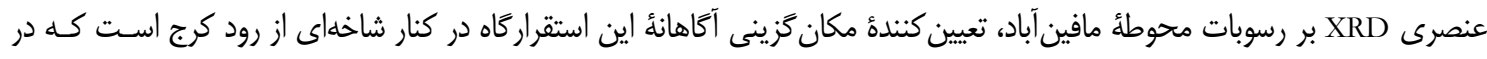

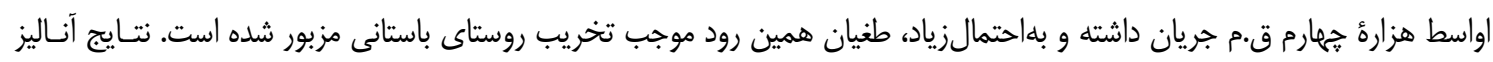

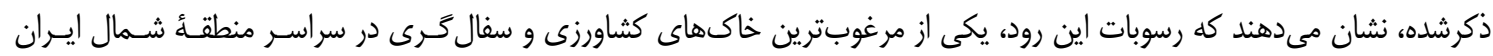

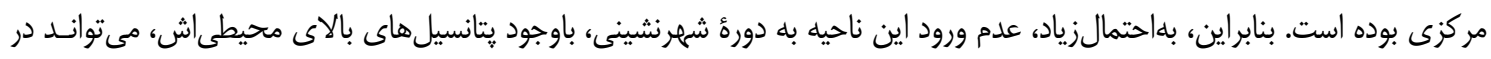

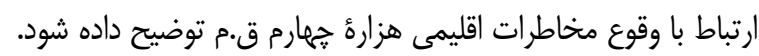

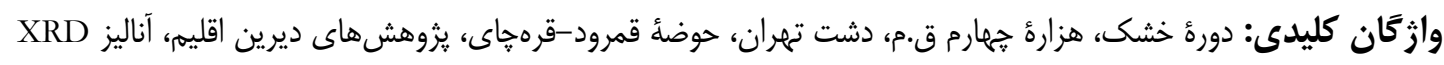

" مسئول مكاتبات: تهران، ميدان امام خمينى، خيابان سى تير، روبروى ساختمان موزه ملى، يزوهشگاه ميراث فرهنگى و گردشكرى،

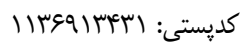

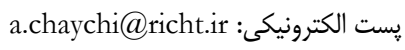
C) حق نشر متعلق به نويسنده(كان) است و نويسنده تحت مجوز Creative Commons Attribution License به مجله اجازه مى دهد مقاله خاب شده

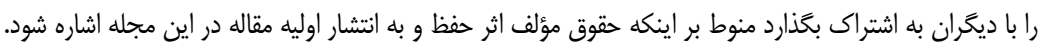


منطقاء فرهنكَى شمال ايران مركـزى در طـى هـزاره

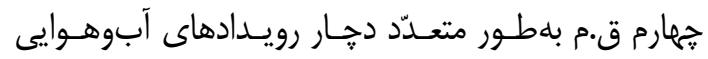

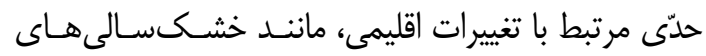

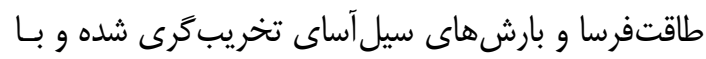

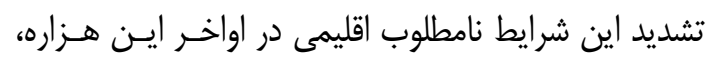

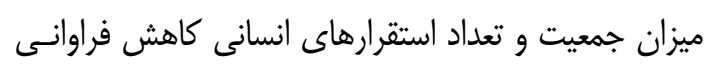

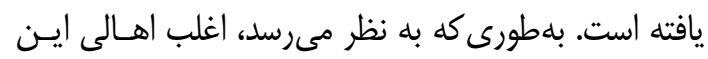

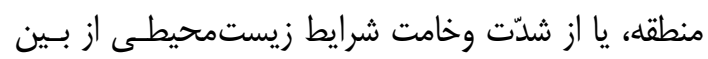

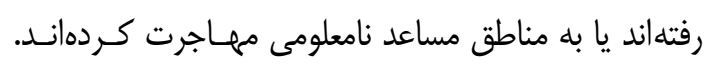

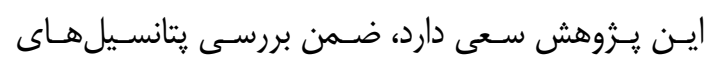

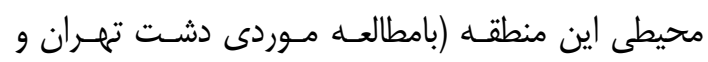

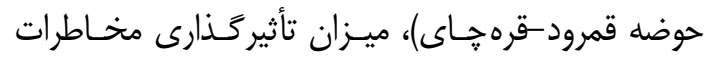

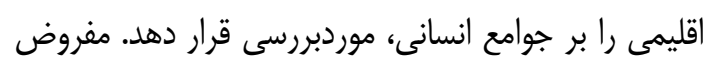

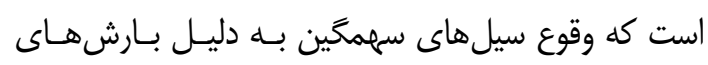

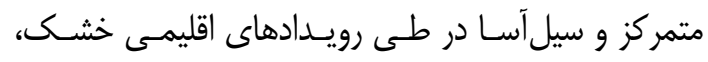
موجب آسيبرسانى جدى بله روسـتاهاى باسـتانى شـمال

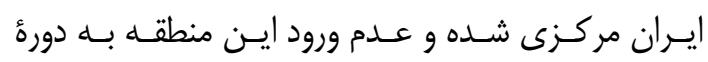

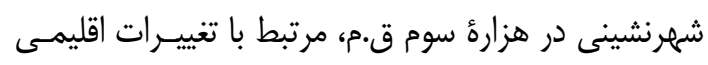

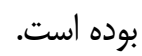

\section{r. شرايط اقليمى هزاره جِهارم ق.م}

ايران به دليل قرار كَرفتن در كمربند يرفشـار جنـب حـارّه

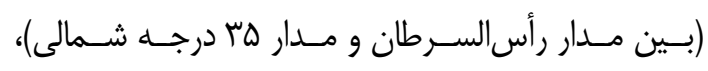

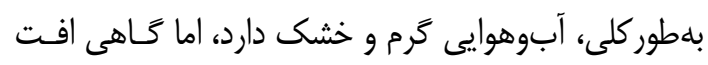

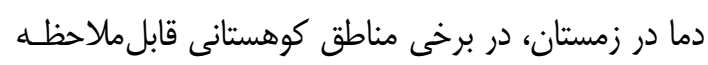

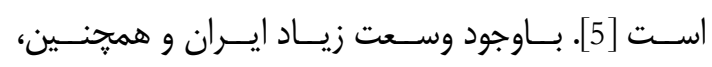

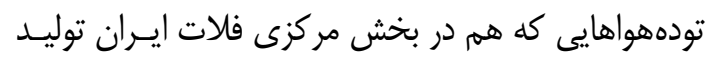

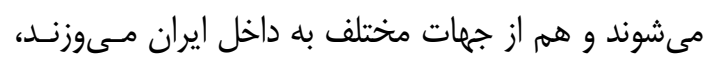

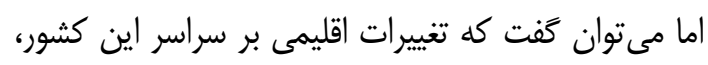
تأثيرات مشابهى مى كذارند (شكل () ). بر طبق يزوهشهاى ديرين اقليم در نيمكره شمالى،

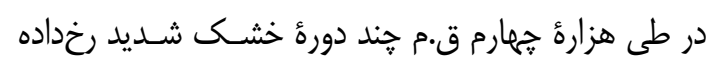

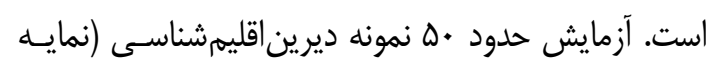

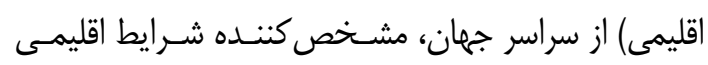

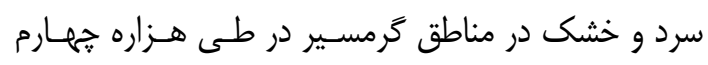

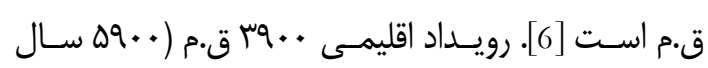

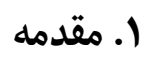

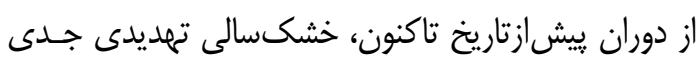
براى موجوديت انسان بوده و اغلب اوقـات، موجـب تغييـر تئر

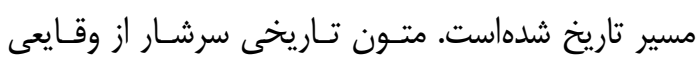

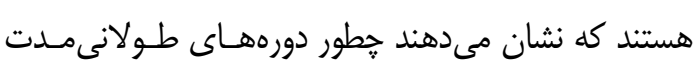

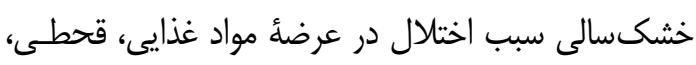

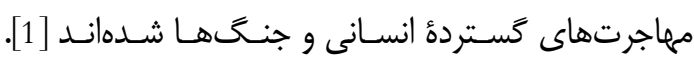

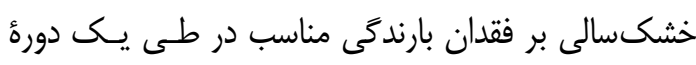

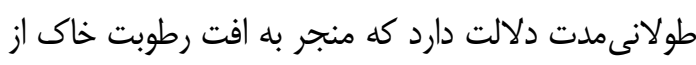

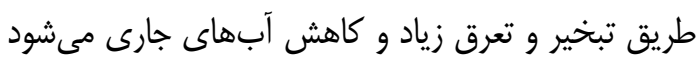

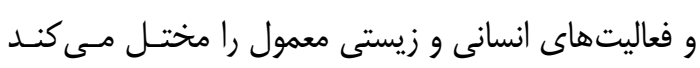

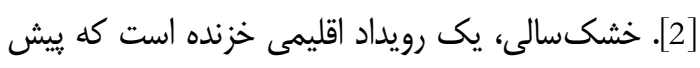

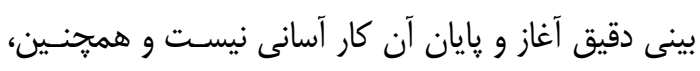

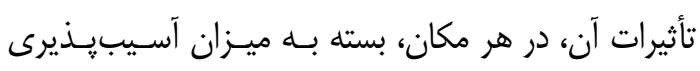

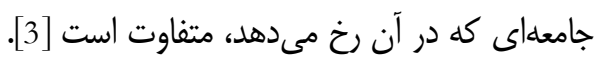

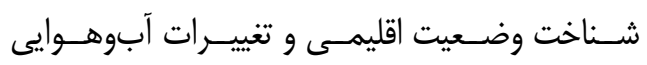

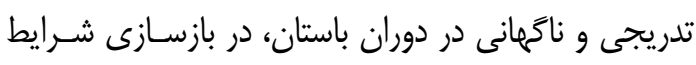

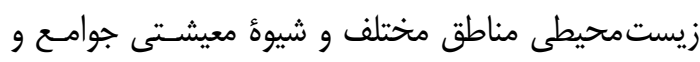

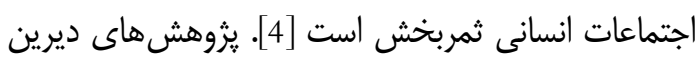

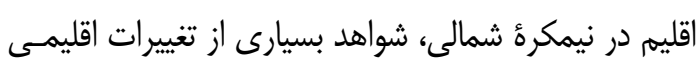

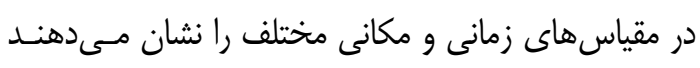

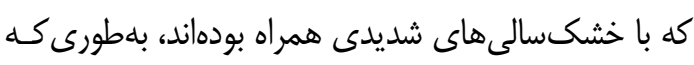

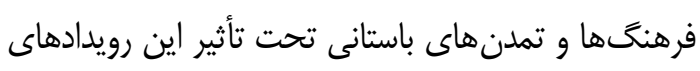

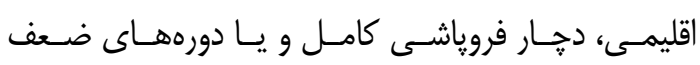

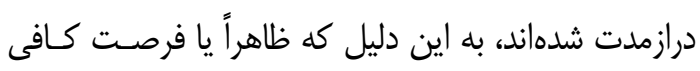

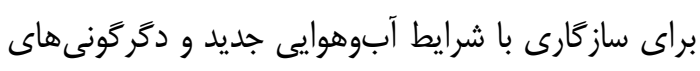

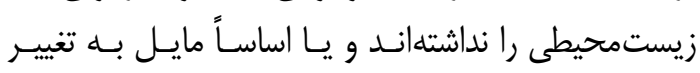

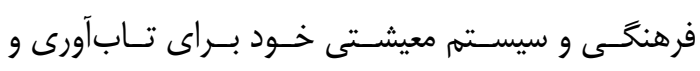

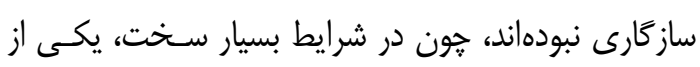

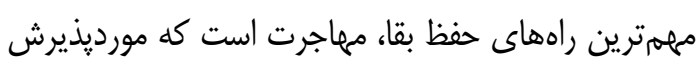

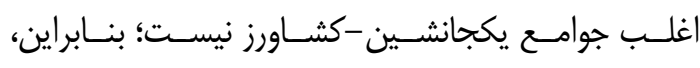

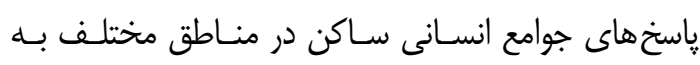

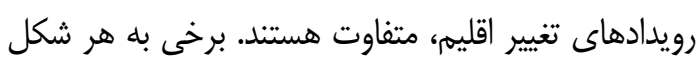

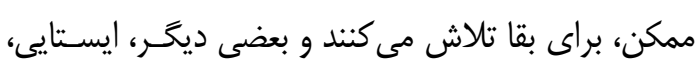

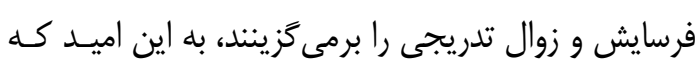
اوضاع جوّى و طبيعى بلزودى بهبود رونى يابد.

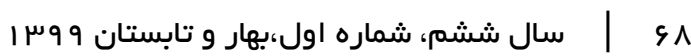




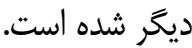

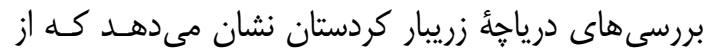

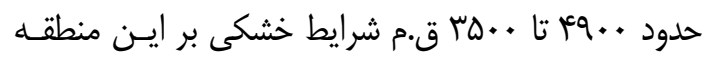

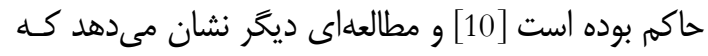

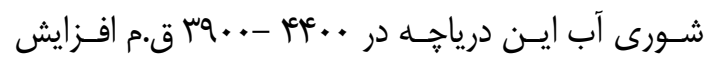

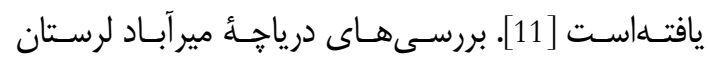

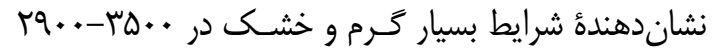
ق.م است [12]. يثوهشهاى ديرين اقليم درياجــ مهـارلو

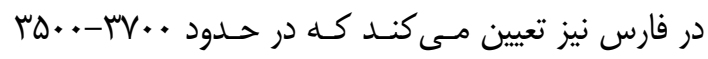

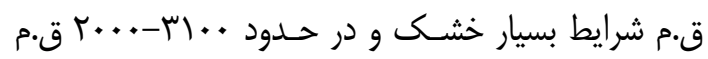

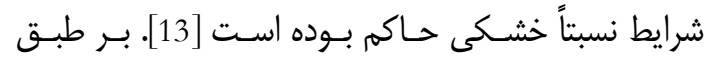

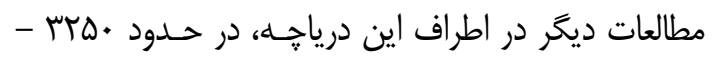

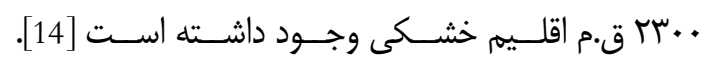

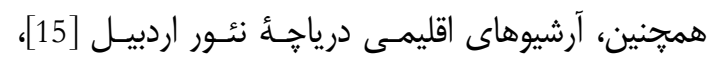

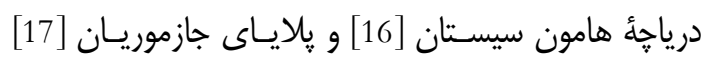

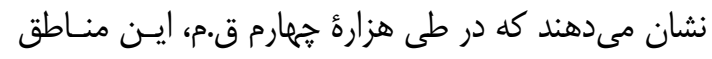

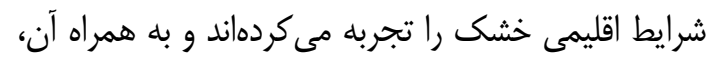

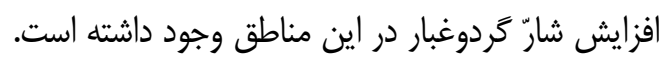
در مركز عراق، دو بررسى ديـريناقلـيمشـناختى در در داسنه
ييش)، جهارمين رويداد سرمايشى جرارد باند است كـه بـاـ

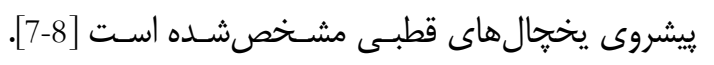

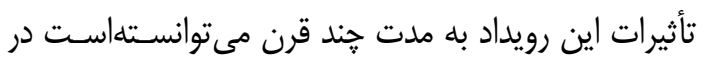

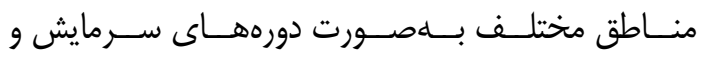

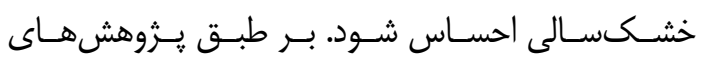

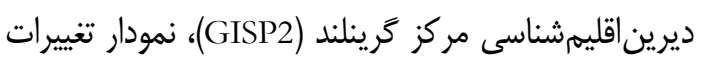

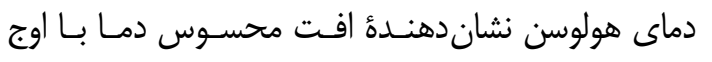

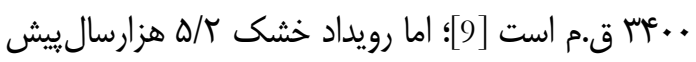

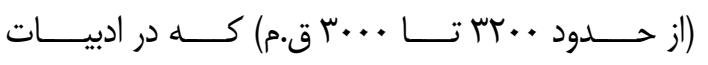

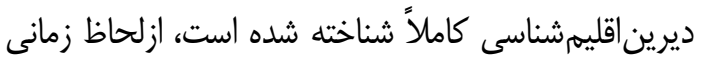

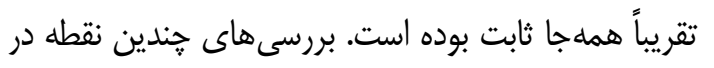

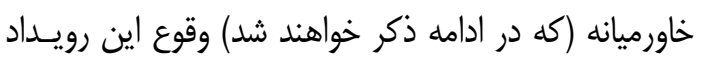

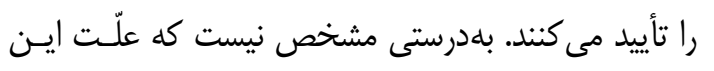

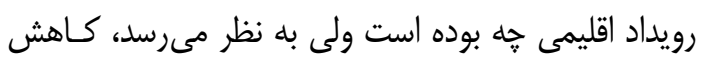

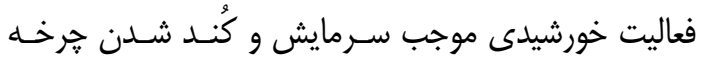

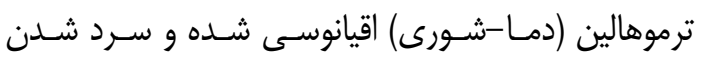
آبهاى اطلس شمالى سبب كاهش تبخير و افـت ميـزان

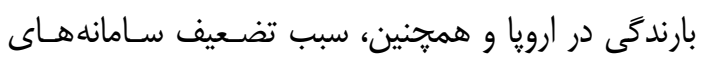

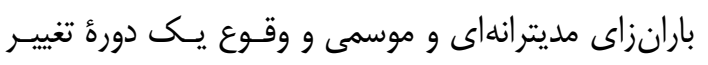

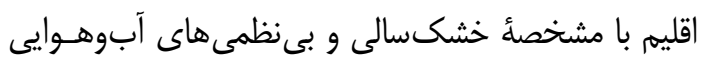

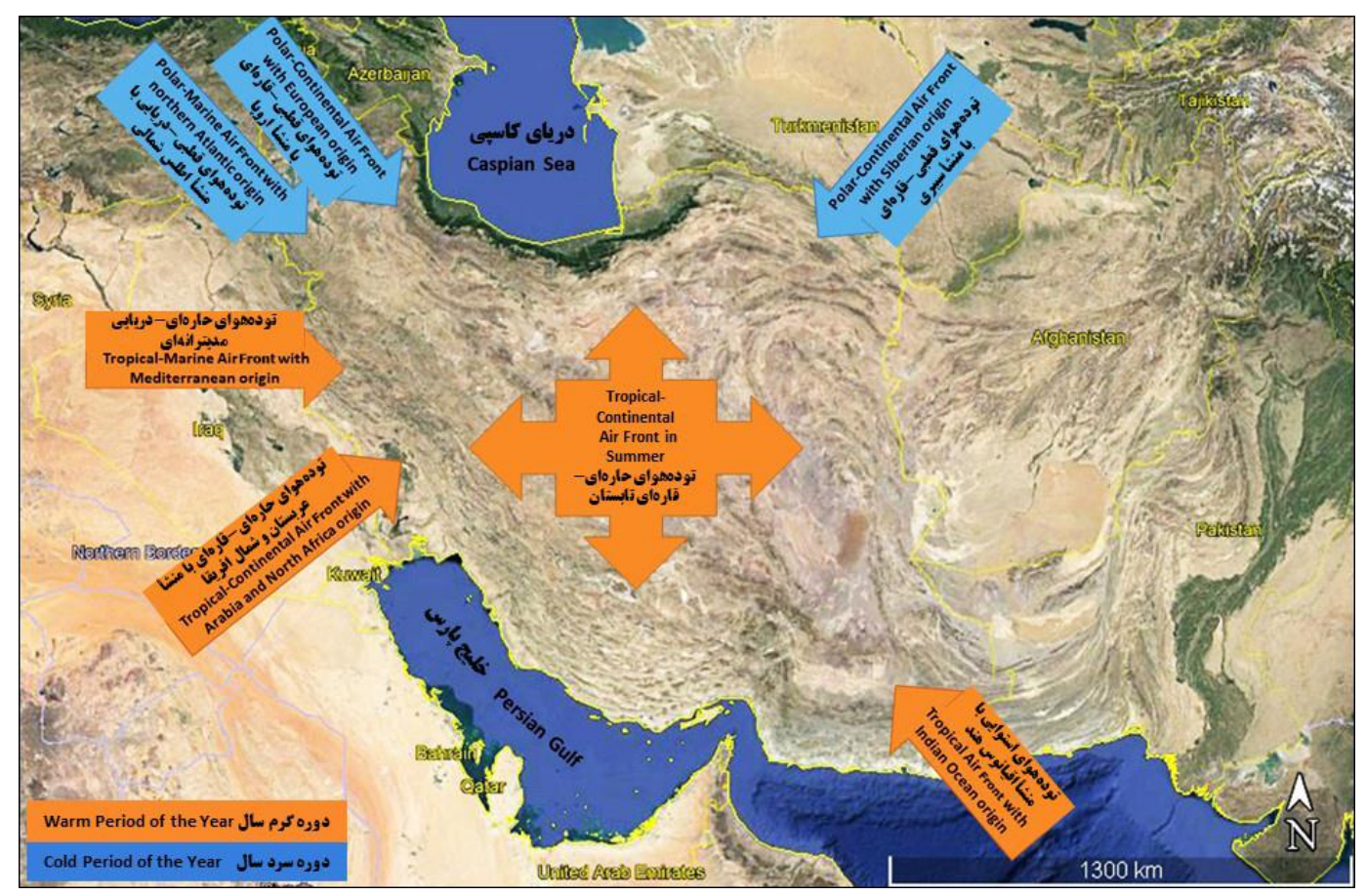

شكل ا: تودهواهاى ايران

Fig. 1: Air fronts of Iran

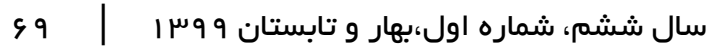




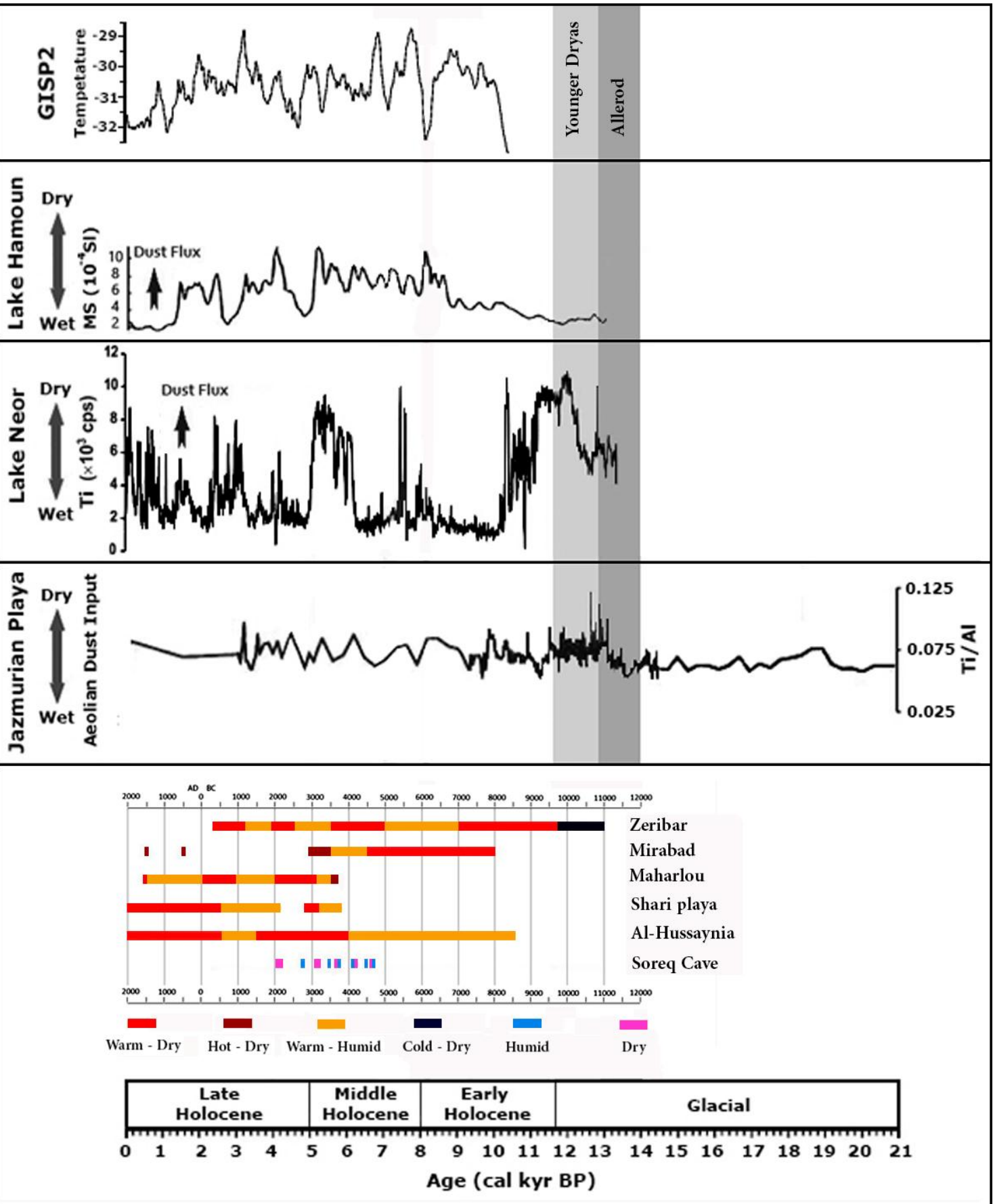

شكل ז: تغييرات اقليمى عصر هولوسن. GISP2 [8]، هامون [16]، نئور [15]، جازموريان [17]، زريبار [11-11 [11، ميرآباد [12]، مهار لو [13]؛

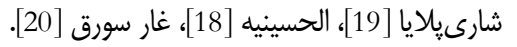

Fig. 2: Holocene Climate change. GISP2 [8], Hamoun [16], Neor [15], Jazmurian [17], Zeribar [10-11], Mirabad [12], Maharlou [13], Shari playa [19], Al-Hussaynia [18], Soreq Cave [20].

نشان مىدهد. مطالعات غار سنگ غار سـورق در نزديكى

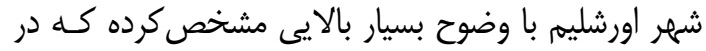

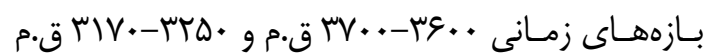
شرايط اقليمى خشكى بـر ايـن منطقـه (شـرق مديترانـه)
الحسينيه [18] و شارى يلايا [19] انجامشده است كه نتايج

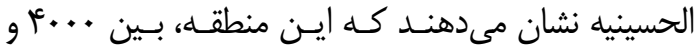

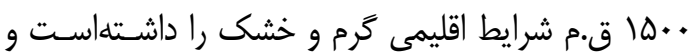

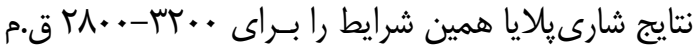

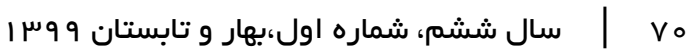


شدند (شكلهاى أو و ه). در گمانه A زير يكلايسه خـاك

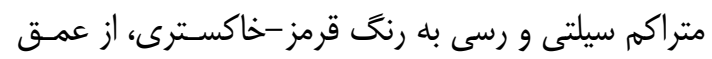

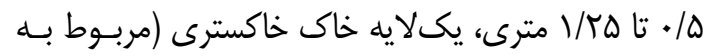

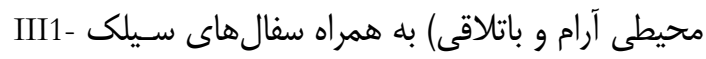

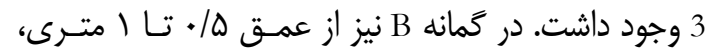

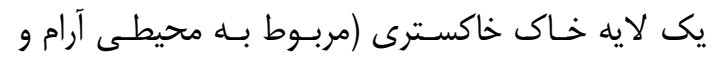

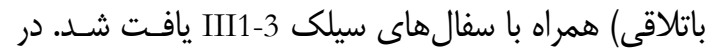

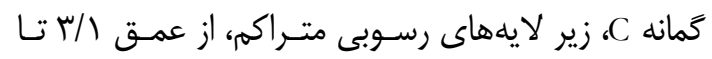

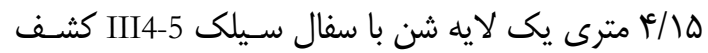

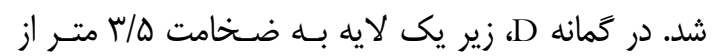

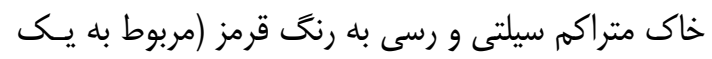

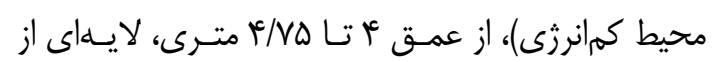

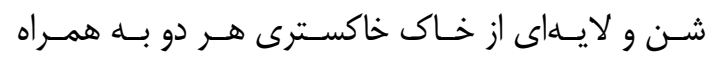

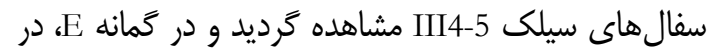

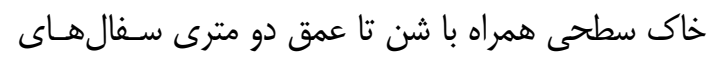

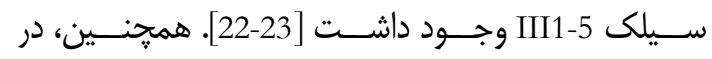

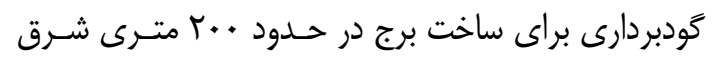

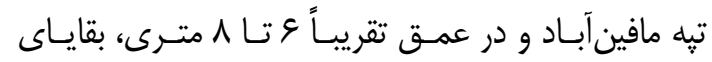

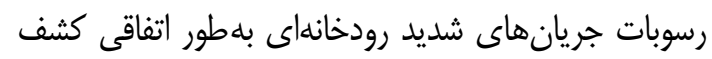

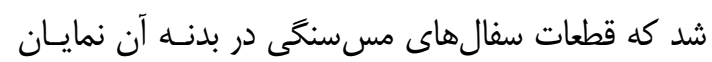

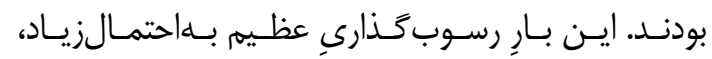

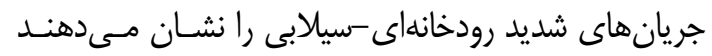

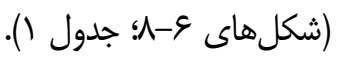

حاكم بوده است [20]. نتايج آناليز مغزهُ رسوبى بستر خليج

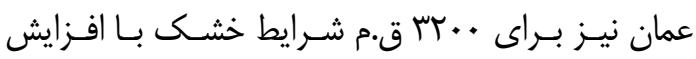

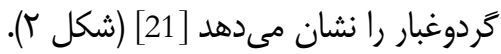

". رسوبشناسى محيطى در محوطههاي باستانى شمال ايران مر كزى مئى

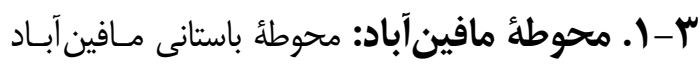

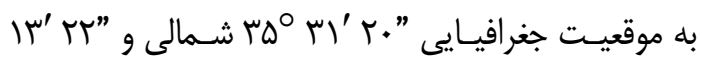

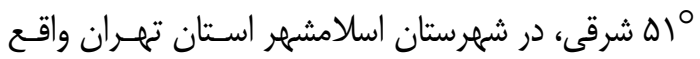

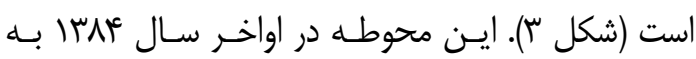

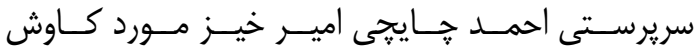

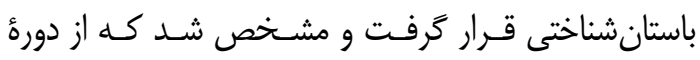

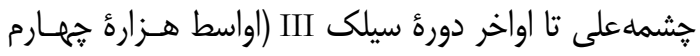

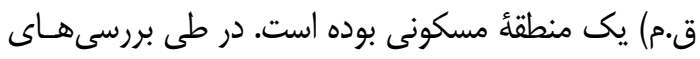

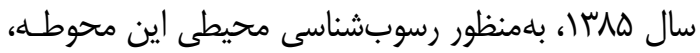

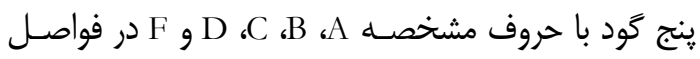

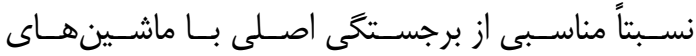

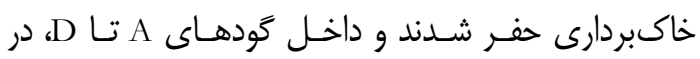

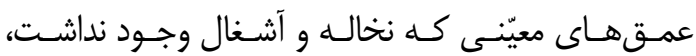

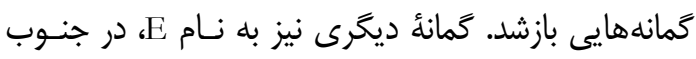

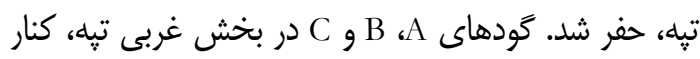

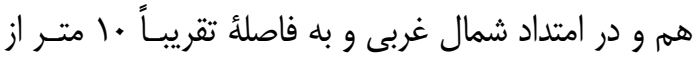

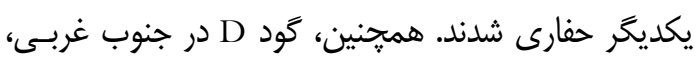

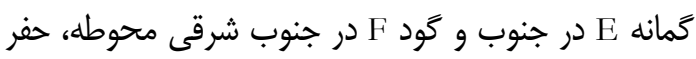

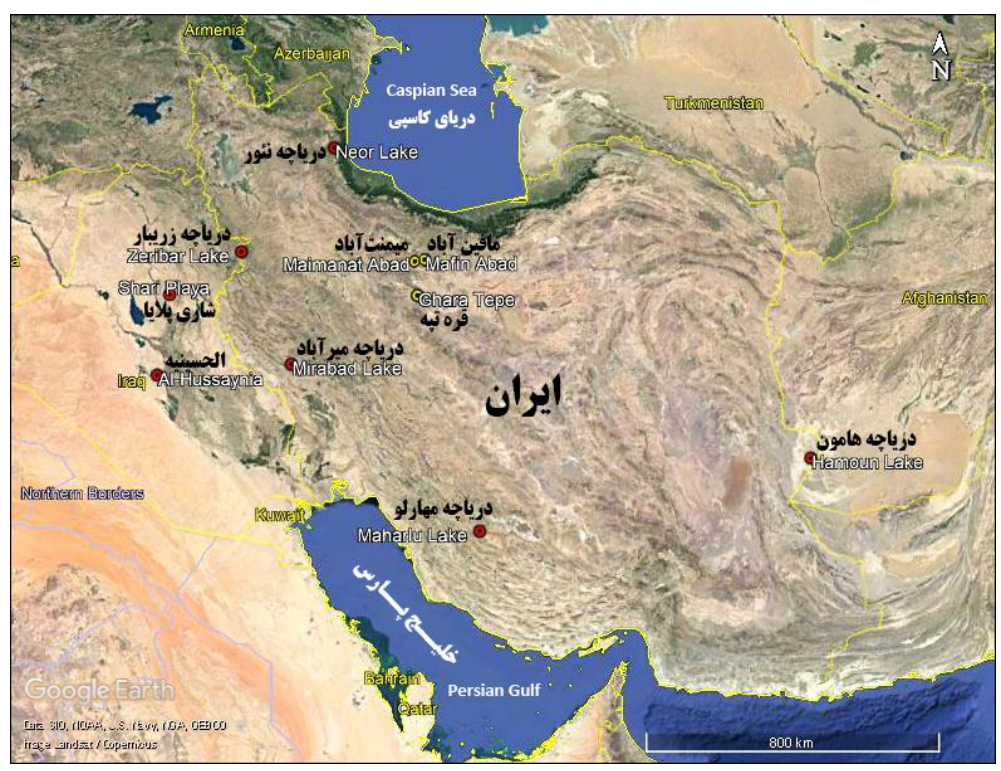

شكل "ا: موقعيت محوطههاى باستانى و محوطههاى ديرين اقليم

Fig. 3: Location of Archaeological and Paleoclimate sites 


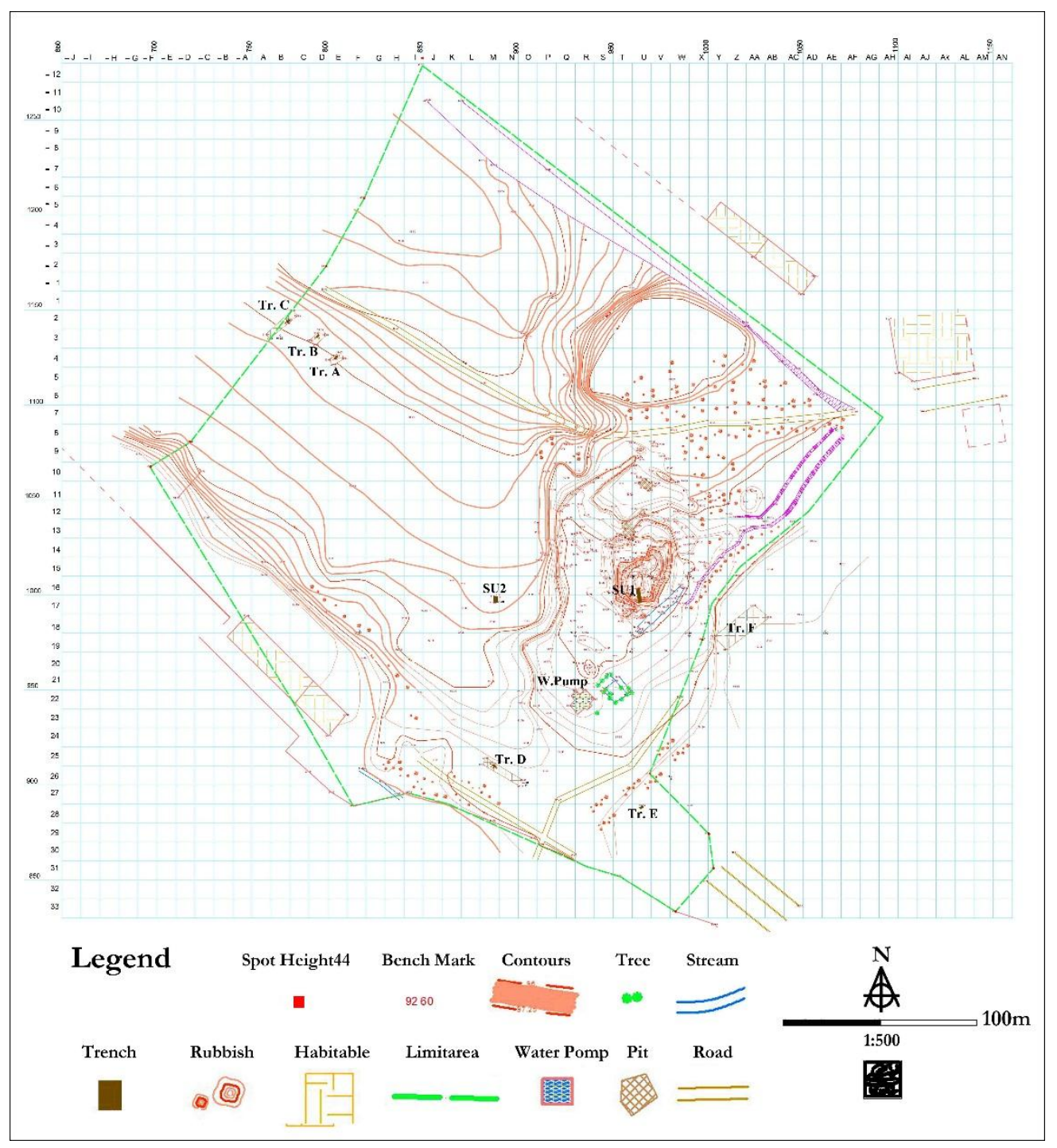

شكل عا: تويوكرافى و موقعيت ترانشههاى محوطة مافين آباد

Fig. 4: Topography of Mafin Abad site and location of trenches

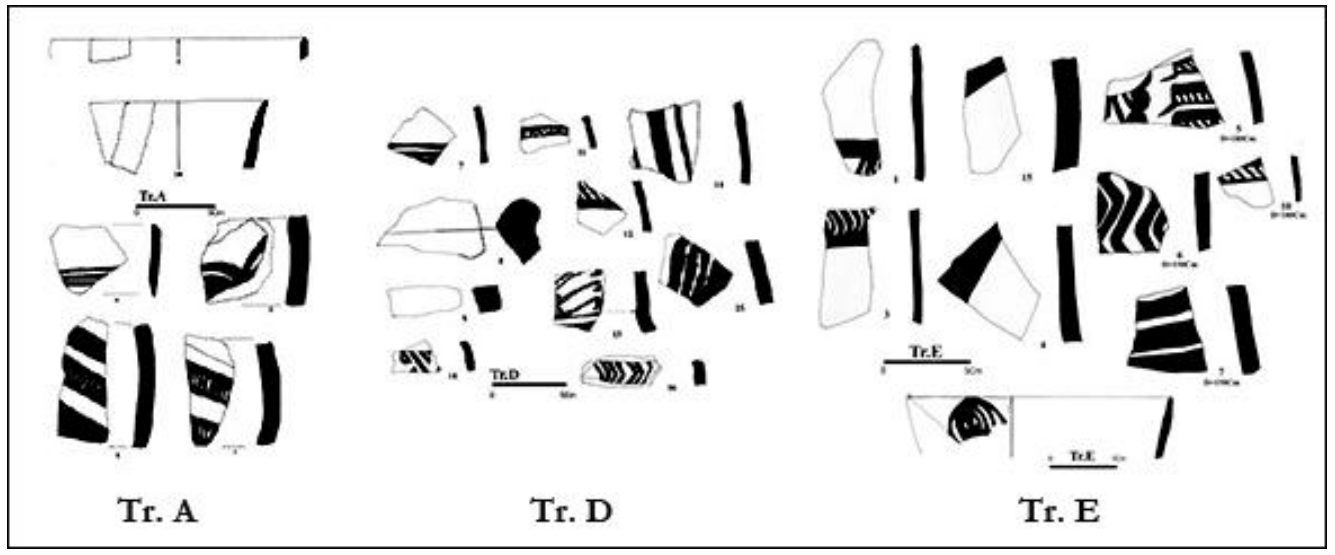

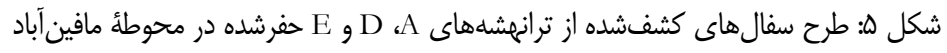

Fig. 5: Pottery of Mafin Abad site found in trenches A, D and E 


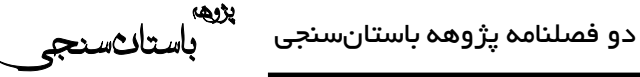

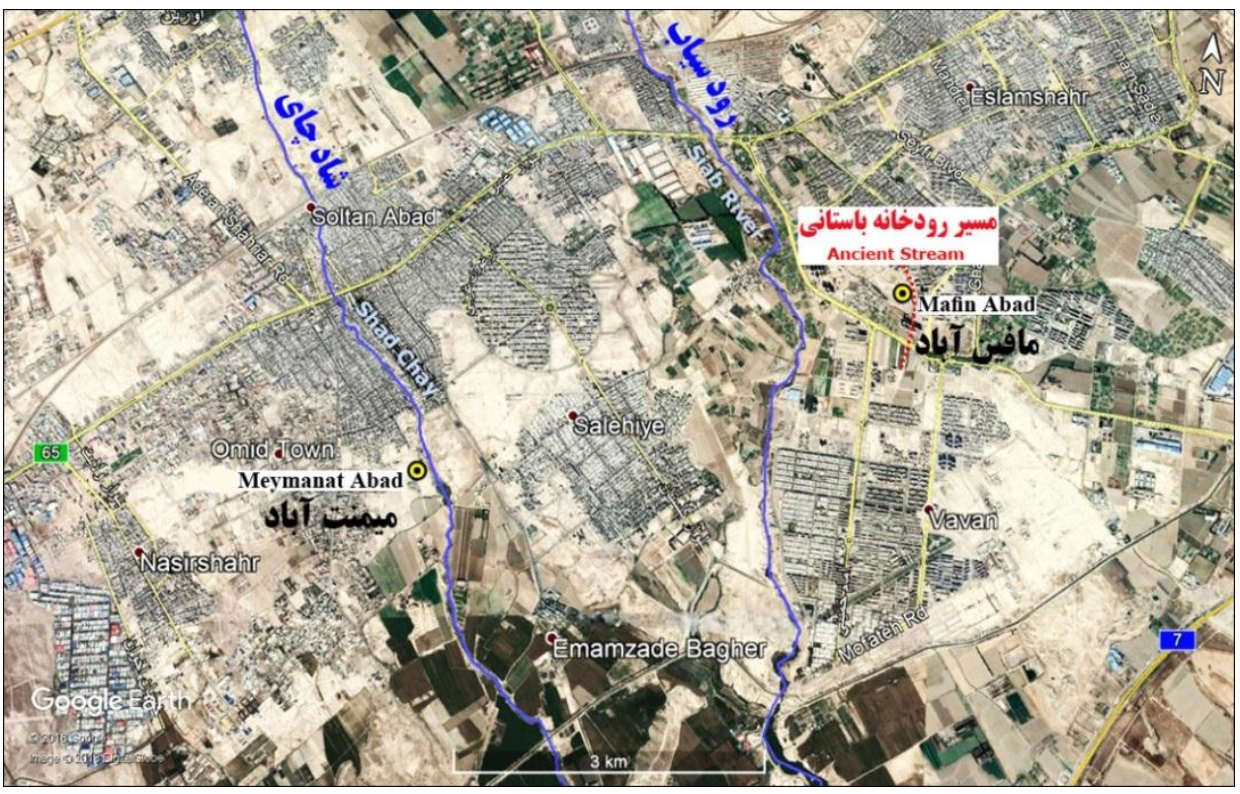

شكل و: موقعيت محوطههاى باستانى مافين آباد و ميمنتآبادو رود باستانى در بخش شرقى محوطه مافينآباد

Fig. 6: Location of archaeological sites of Mafin Abad and Meymanat Abad and ancient river in the east of Mafin Abad site

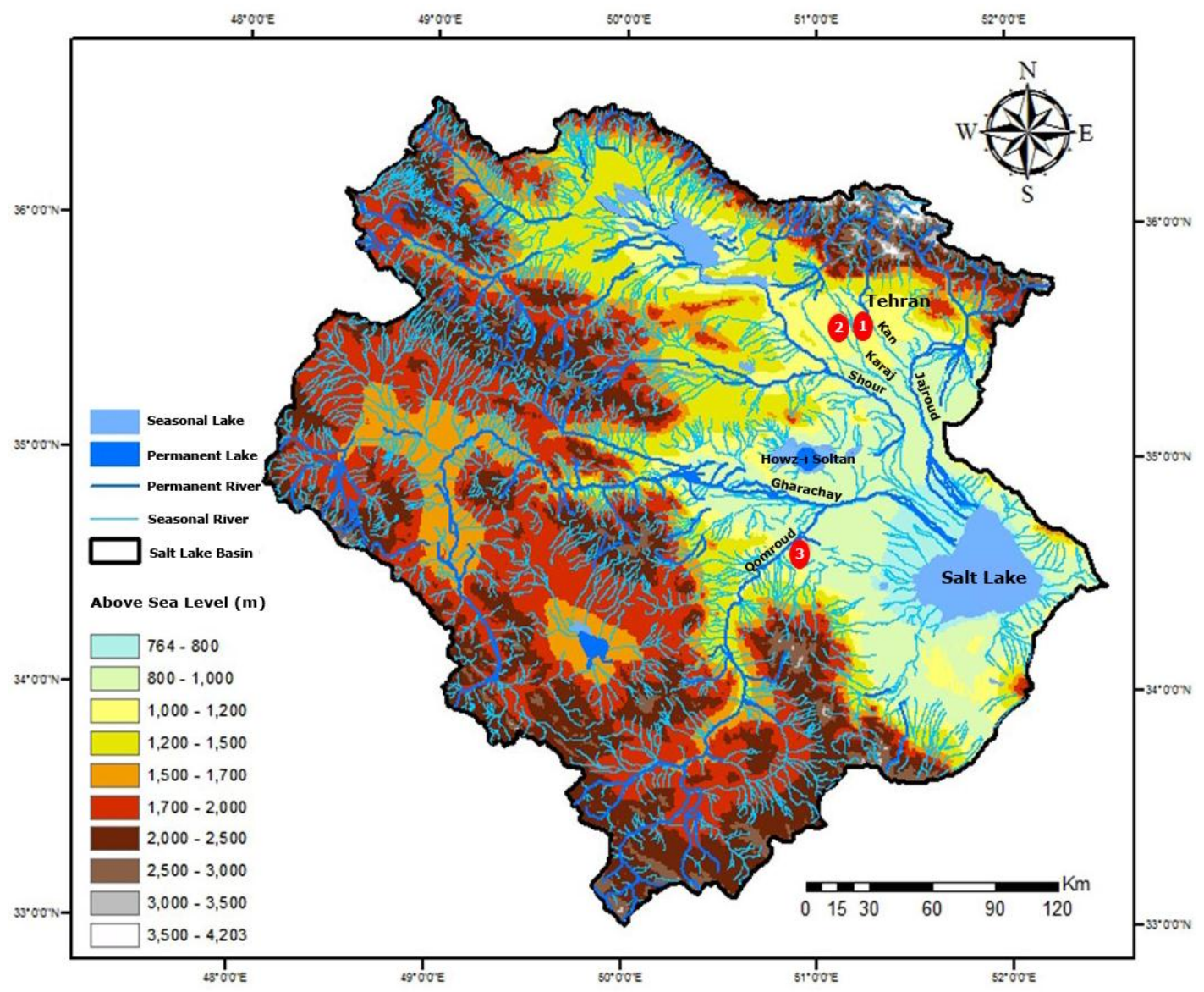

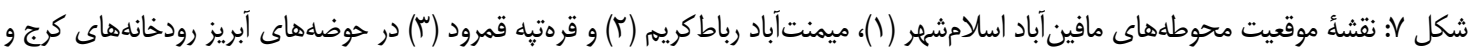
قمرود-قرهجاى

Fig. 7: ArcGIS map of location of Mafin Abad (1), Meymanat Abad (2) and Ghara Tepe Qomroud (3) in the Karaj and Qomroud-Gharachay Basins 


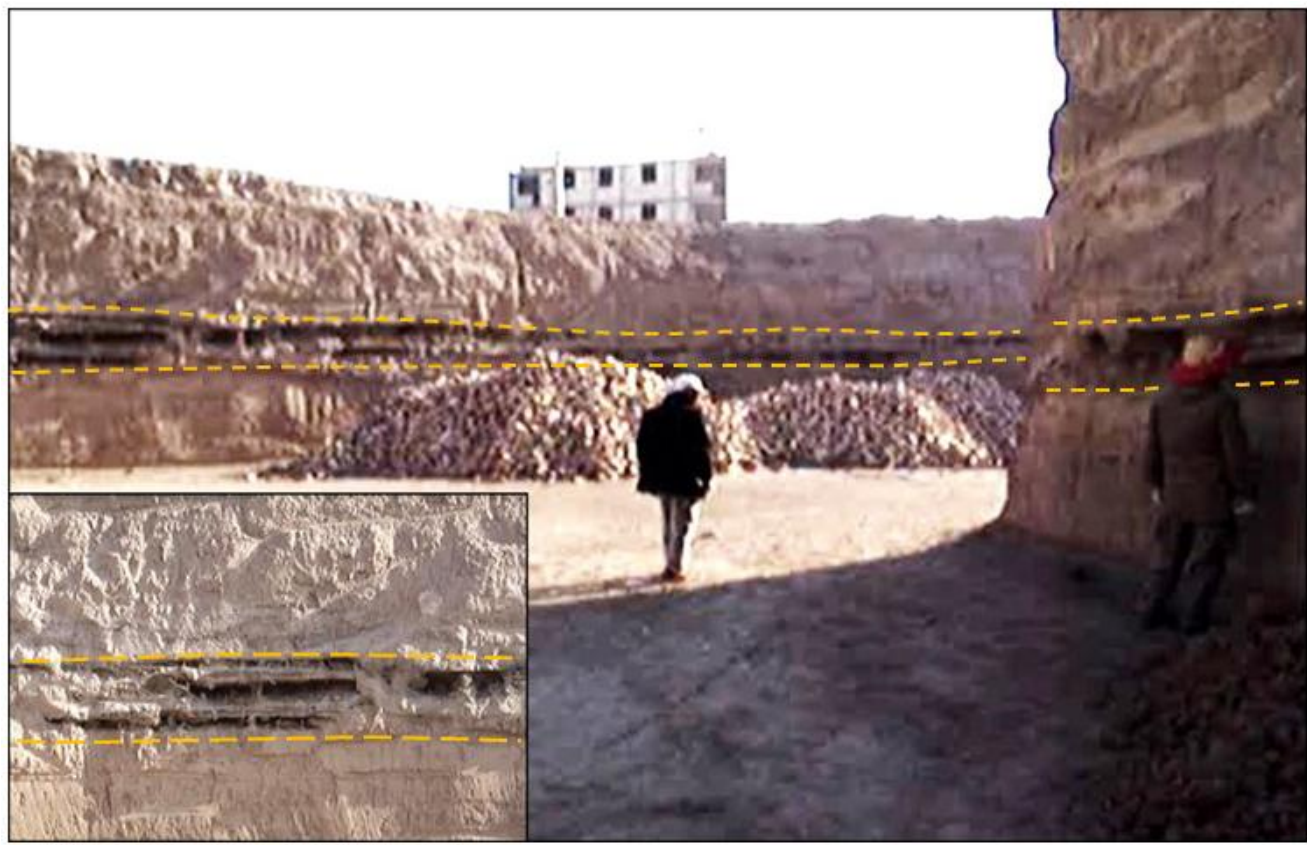

شكل م: شواهد جريان آبى باستانى در بخش شرقى محوطه مافين آباد

Fig. 8: Evidence of an ancient stream in the east of Mafin Abad site

قرهتِه در اواسط هزاره جهارم ق.م وقوع يك سيل عظيم

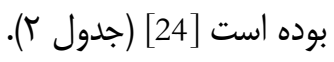

ץ-T. محوطة ميمنتآباد: محوطة باستانى ميمنت آباد

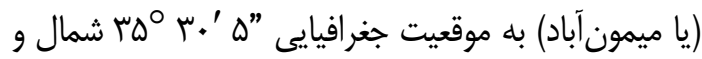

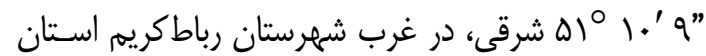
تهران واقع است (شكلهاى 9 و V)، اين محوطه شامل دو دران

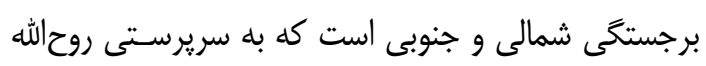
يوسفى زُشك در سال (وسا كاوش شدهاست و شـواهدى

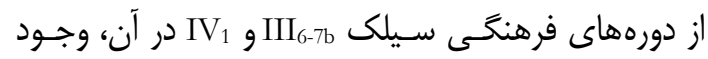

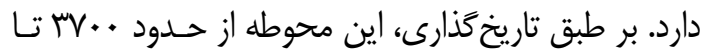

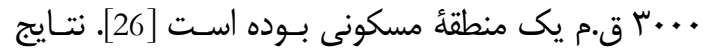

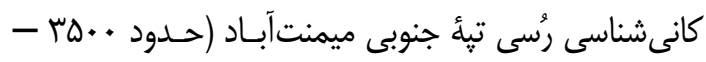

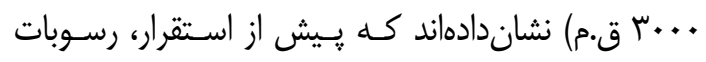
حاصل از طغيان رودخانه، سطح زمين را يوشانده بودهانـــا.

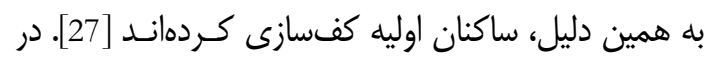

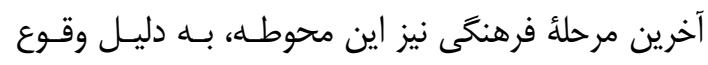

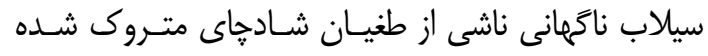

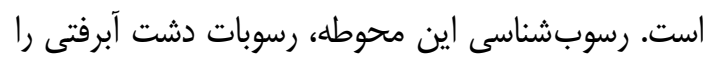

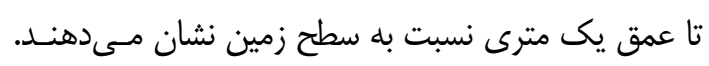

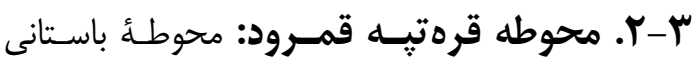

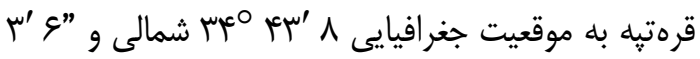

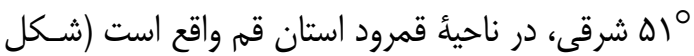

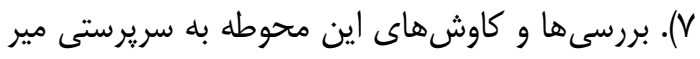

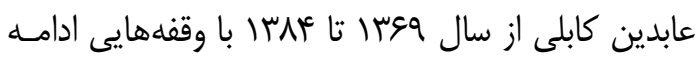

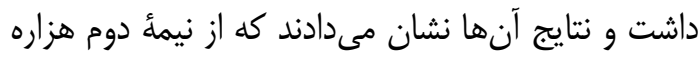

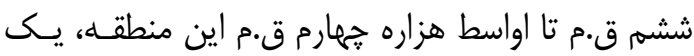

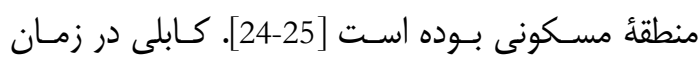

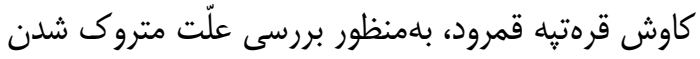

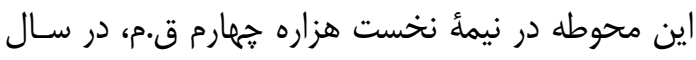

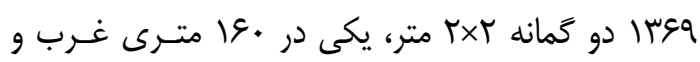

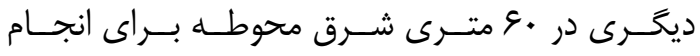
رسوبشناسى محيطى حفر كـرد. بـاوجودى كـه نتيجـهـ

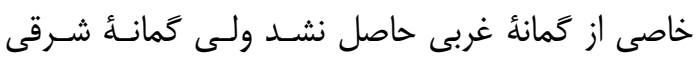

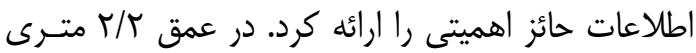

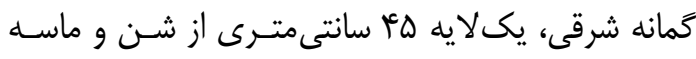

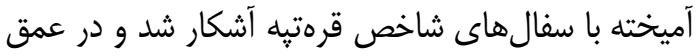

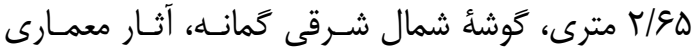

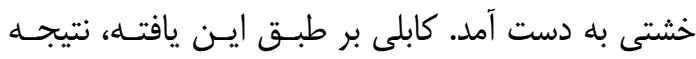

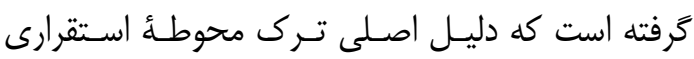

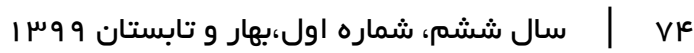




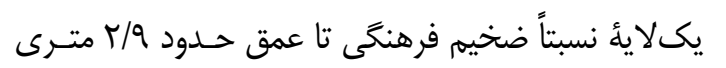

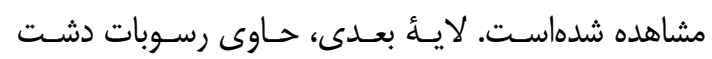

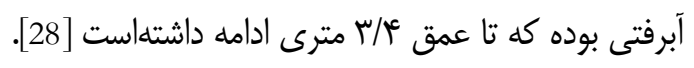

زير اين لايه، به عمق حدود +r سـانتىمتـر بقايـاى يـك

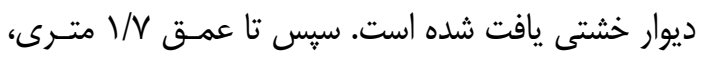

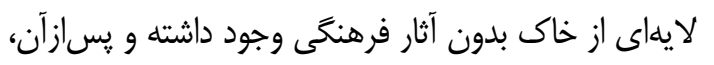

جدول 1: "مانههاى رسوبشناسى محيطى محوطه مافين آباد

Table 1: Pits of environmental sedimentology in Mafin Abad site

\begin{tabular}{|c|c|c|c|c|c|c|}
\hline $\mathbf{F}$ & $\mathbf{E}$ & $\mathbf{D}$ & C & B & $\mathbf{A}$ & $\begin{array}{c}\text { Depth } \\
\text { (Cm) }\end{array}$ \\
\hline \multirow{9}{*}{$\begin{array}{l}\text { Constructio } \\
\text { n debris } \\
\text { And brick } \\
\text { kiln waste } \\
\text { ضالئ ساختمانى كورة و آجريزى }\end{array}$} & \multirow{8}{*}{ 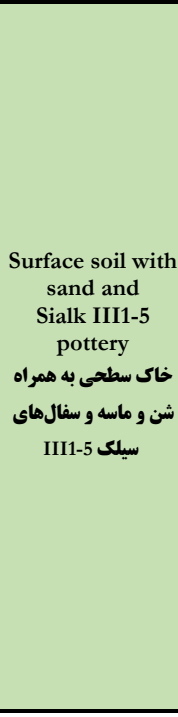 } & \multirow{2}{*}{$\begin{array}{l}\text { Surface soil } \\
\text { خاك سطحى }\end{array}$} & $\begin{array}{c}\text { Surface soil } \\
\text { خاك سطحى }\end{array}$ & \multirow{2}{*}{$\begin{array}{l}\text { Surface soil } \\
\text { خاك سطحى }\end{array}$} & \multirow{2}{*}{$\begin{array}{c}\text { Dense red-gray clay } \\
\text { soil } \\
\text { خاكى متراكم رسى -خاكسى }\end{array}$} & 25 \\
\hline & & & $\begin{array}{l}\text { Soil and stone } \\
\text { خاك و سنك }\end{array}$ & & & 50 \\
\hline & & \multirow{14}{*}{$\begin{array}{l}\text { Dense red clay soil } \\
\text { (low energy } \\
\text { environment) }\end{array}$} & $\begin{array}{l}\text { Sand, pieces of } \\
\text { nylon and fabric }\end{array}$ & $\begin{array}{l}\text { Gray soil with } \\
\text { Sialk III1-3 pottery } \\
\text { (swampy environment) }\end{array}$ & \multirow{3}{*}{ 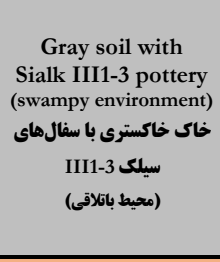 } & 75 \\
\hline & & & و و إرجه & خاك خاكسترى با سفالهاى III1-3 (محيط باتلاقى) & & 100 \\
\hline & & & \multirow{2}{*}{$\begin{array}{l}\text { Gray soil } \\
\text { خاك تيره }\end{array}$} & \multirow{4}{*}{$\begin{array}{c}\text { Dense red clay soil } \\
\text { (low energy } \\
\text { environment) } \\
\text { خاكى متراكم رسى قرميط (محرئ) }\end{array}$} & & 125 \\
\hline & & & & & \multirow{3}{*}{ 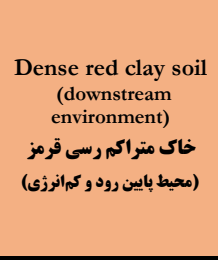 } & 150 \\
\hline & & & \multirow{4}{*}{$\begin{array}{c}\text { Dense red clay soil } \\
\text { (low energy } \\
\text { environment) } \\
\text { خاكى متراكم رسى قر مز محيط (مرزى) }\end{array}$} & & & 175 \\
\hline & & & & & & 200 \\
\hline & & & & & & 225 \\
\hline & & & & & & 250 \\
\hline & & & $\begin{array}{l}\text { Dense pale brown } \\
\text { clay soil (downstream } \\
\text { environment) }\end{array}$ & & & 275 \\
\hline & & & 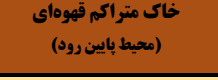 & & & 300 \\
\hline & & & & & & 325 \\
\hline & & & $\begin{array}{l}\text { Sand with the Sialk } \\
\text { III4-5 pottery }\end{array}$ & & & 350 \\
\hline & & & 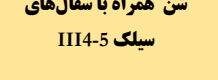 & & & 375 \\
\hline & & & & & & 400 \\
\hline & & $\begin{array}{l}\text { Sand with the Sialk } \\
\text { III4-5 pottery }\end{array}$ & Dense red clay soil & & & 425 \\
\hline & & سيلك III-5 & & & & 450 \\
\hline & & $\begin{array}{c}\text { Gray soil and sand } \\
\text { with Sialk III4-5 } \\
\text { pottery } \\
\end{array}$ & & & & 475 \\
\hline & & & & & & 500 \\
\hline
\end{tabular}

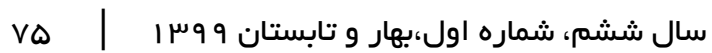


جدول r: گمانه دوم رسوبشناسى محيطى قرهتيه قمرود

Table 2: The second trench of environmental sedimentology in Ghara Tepe of Qomroud

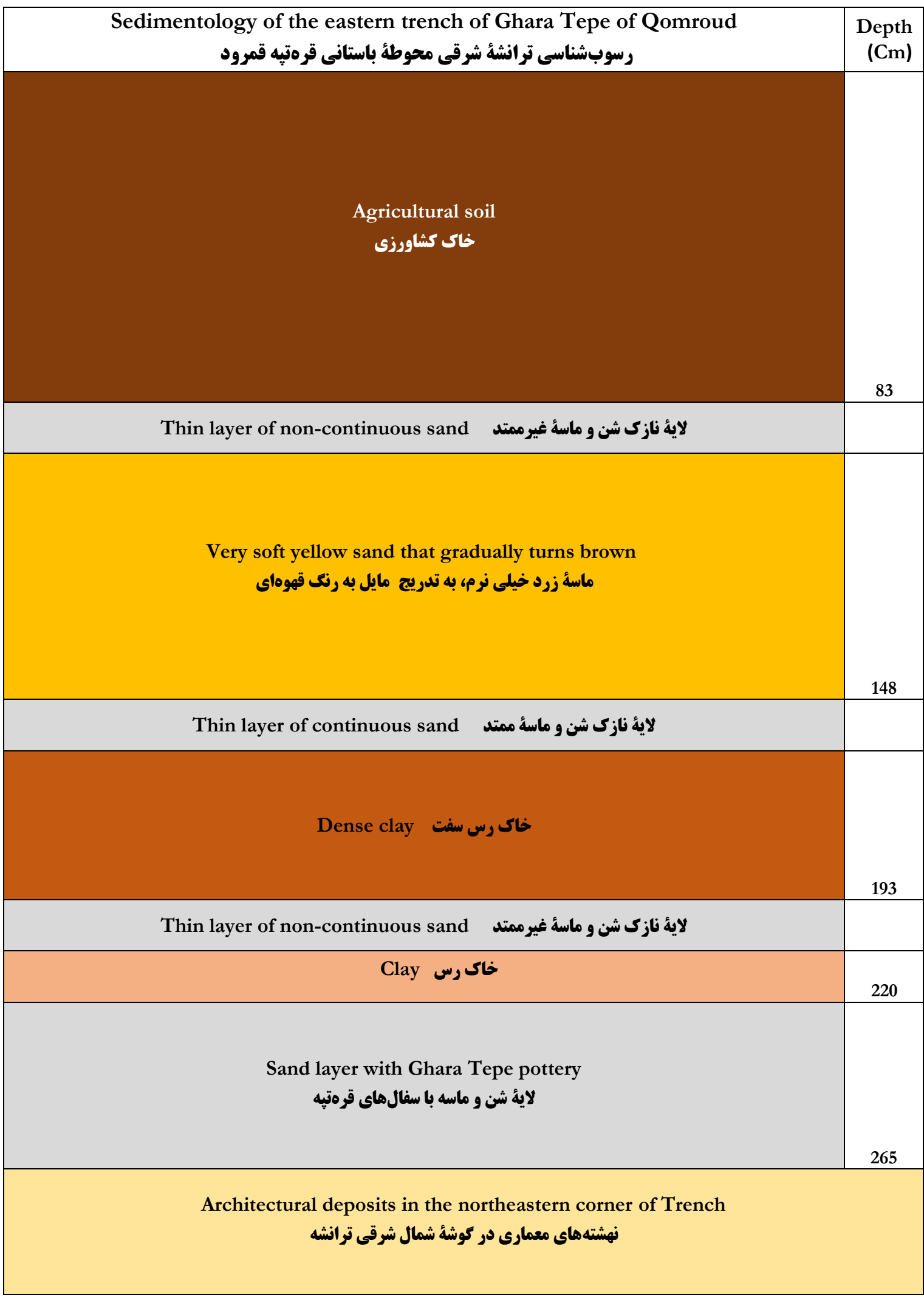


جدول سا: كانىهاى موجود در نمونه XRD رسوبات محوطه مافين آباد

Table 3: Minerals in XRD sample of Mafin Abad sediments

\begin{tabular}{|c|c|}
\hline Chemical Formula / فرمول شيميايی & نام نمونه / Compound Name \\
\hline$(\mathrm{Ca}, \mathrm{Mg}) \mathrm{CO} 3$ & كلسيت / Calcite \\
\hline $\mathrm{SiO} 2$ & كوارتز / Quartz \\
\hline${ }_{10}(\mathrm{OH})_{8}(\mathrm{Si}, \mathrm{Al})_{4} \mathrm{O}(\mathrm{Mg}, \mathrm{Fe}, \mathrm{Al})_{6}$ & كلريت / Chlorite \\
\hline $\mathrm{K}_{1-1,5} \mathrm{Al}_{4}\left(\mathrm{Si}_{7-6,5} \mathrm{Al}_{1-1,6}\right) \mathrm{O}_{20}(\mathrm{OH})_{4}$ & ايليت / Illite ا \\
\hline KAlSi3O8 & فلدسيات و كانىهاى رسى / Feldspar and clay minerals \\
\hline
\end{tabular}

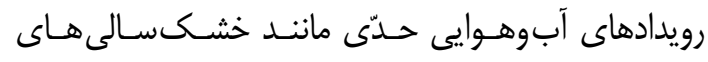

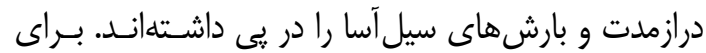

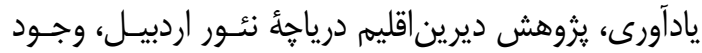

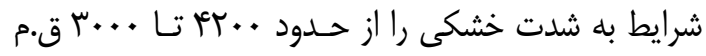
نشان مىدهد؛ مطالعـات غـار سـورق در شـرق مديترانها،

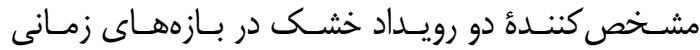

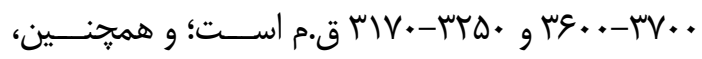
آرشيوهاى اقليمى كف خليج عمـان تعيـين كنتـدهُ شـرايط

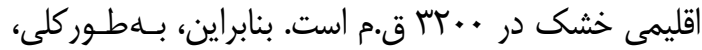

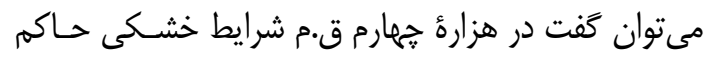
بوده كه در برخى زمان ها، بلطور طاقت فرسايى، بر شـدّت

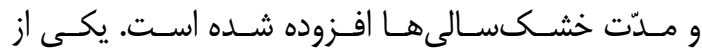
مشخصات اصلى دورههاى خشك، افزايش مـدّت فصـول كرم سال، كاهش بارندگى سالانه، خشكى و نفوذنايـــيرى خاك، وقوع بارندگى هاى متمركز و سيل آسا و جارى شدان

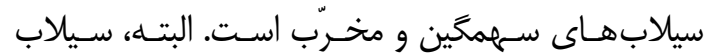
همان گَونه كه ويرانخر بوده است، در مواردى مسىتوانسـته

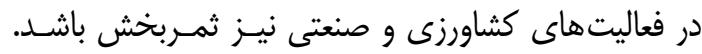

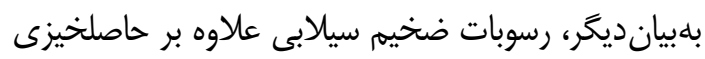
خاك، عرصه را براى فعاليتهاى صنعتى مانند سـفالكرى و ساخت سردوك نيز فراهم مى كرده است. در طى بررسى هاى محيطى محوطـــ مـافين آبـاد، شواهد، وجود يك رود باستانى را نشان مى دهند كه يكان محانى از انشعابات رود كرج در اواسط هـز ارهٔ جههـارم ق.م بـوده است. به احتمال زياد، طغيان همين رود موجب تخريسب روستاى باستانى مزبور شده است. آنـاليز XRD رسـوبات رديات اين رود، تعيين كننده مكان كزينى آكاهانأئ اين استقر اركاه مهم هزارههاى ينجم و جهارم ق.م اسـت. نتـايج نشـان

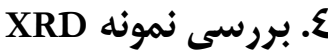

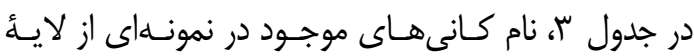
خاك آمدهاست كه همه كانىهاى مذكور، بلصورت خـرده در تمام لايه خاكهاى موردبررسى محوطـه مـافين آبـاد

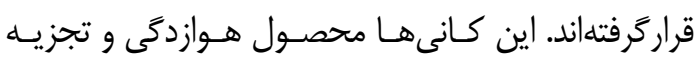
شيميايى موجود در سطح زمين هستند. سيليس موجود در

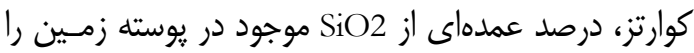

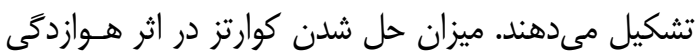

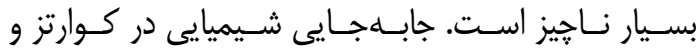

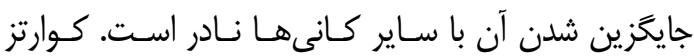

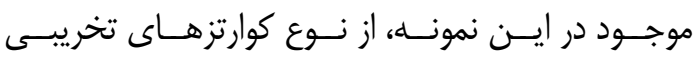

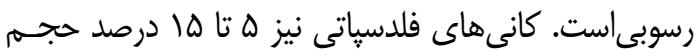
سنخَهاى تخريبى عادى را تشكيل مسى دهنـد و بالينكـهـ

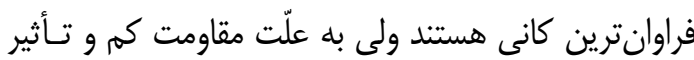
سريع هوازدمى، نسبت آنها در رسوبات بسيار קبايين است.

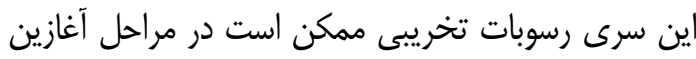

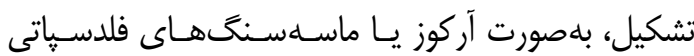

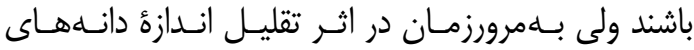

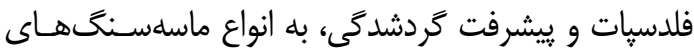

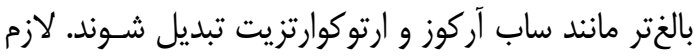

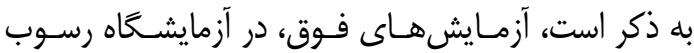

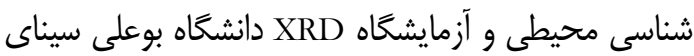

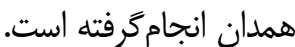

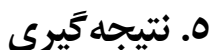

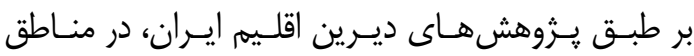

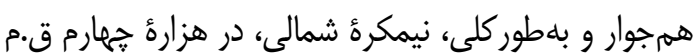

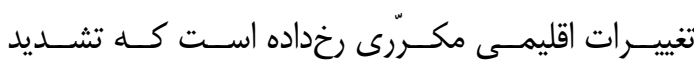




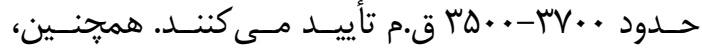

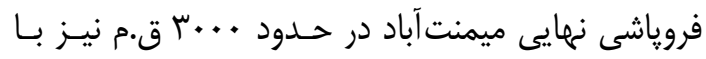

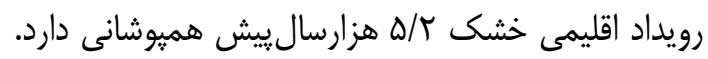

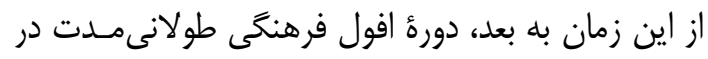

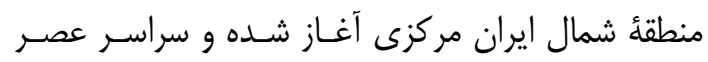

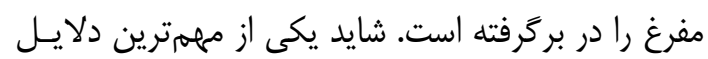

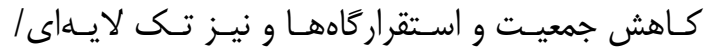

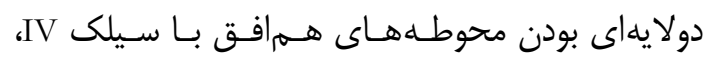
افزايش و تشديد رويدادهاى آبوهوايى حدّى بوده باشد.

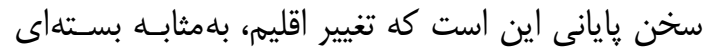

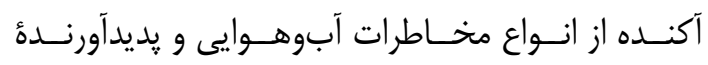

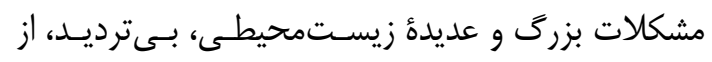

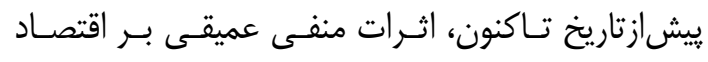

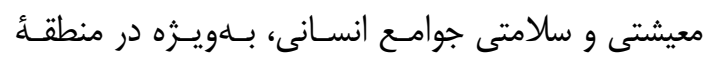

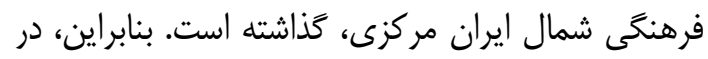

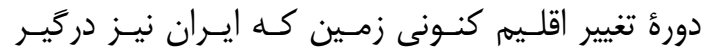

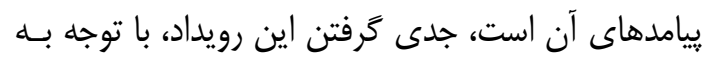
ييشينة آن، ضرورى به نظر مىرسد.

\section{سياسگزارى}

از آقايان دكتر آرش شريفى و دكتر رضا صفايىراد بهخاطر

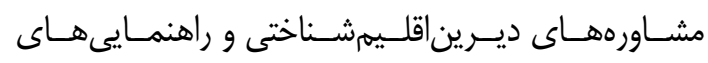

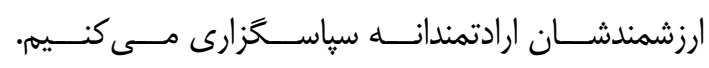

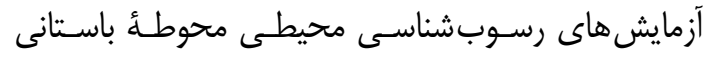

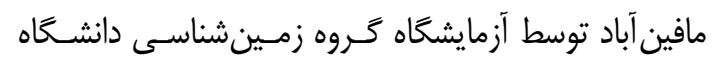
بوعلىسيناى همدان انجام شده است. بنـابراين، در اينجـا

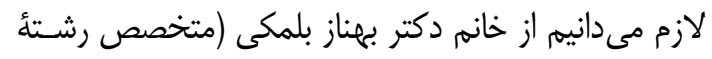

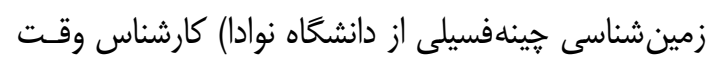

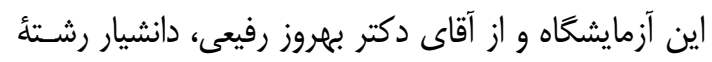
زمين شناسى زيستمحيطى دانشخاه بوعلى سينا صـميمانه

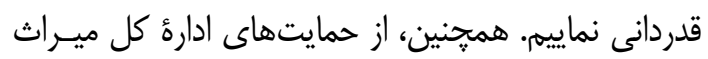

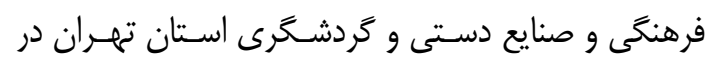

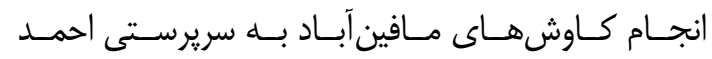
جايجىاميرخيز كمال تشكر را داريم.
مىدهند كه رسـوبات ايـن رود، يكسى از مرغـوبتـرين

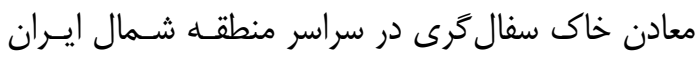
مركزى بوده است. يِيشتر نيز در كنار محوطأه مافين آباد

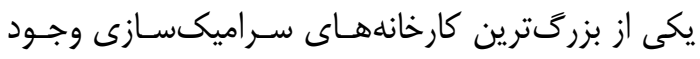

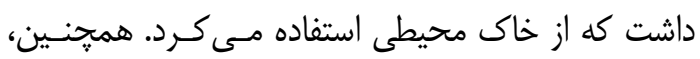

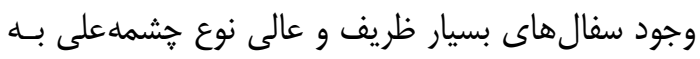

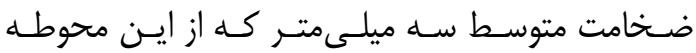

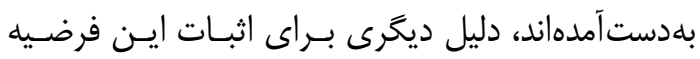

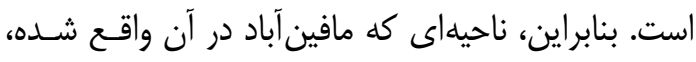

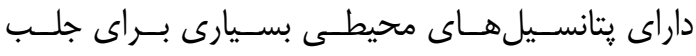

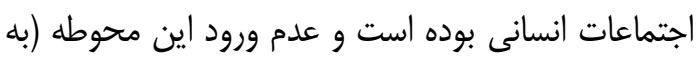

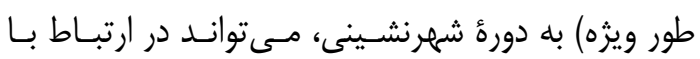
تغييرات اقليمى و محيطى توضيح داده شود.

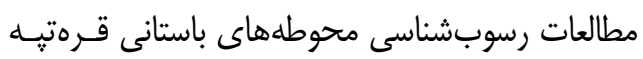

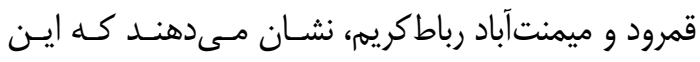
محوطهها نيز به دليل وقوع سيل از بين رفتهاند. مافين آباد آناد إندان و قرهتيه در اواسط هزارهٔ جِهارم ق.م و ميمنت آباد در اواخر

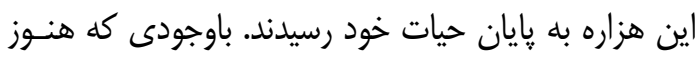

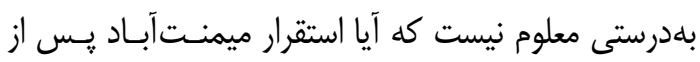

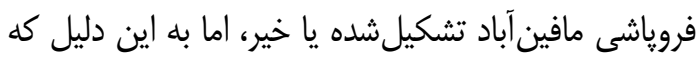

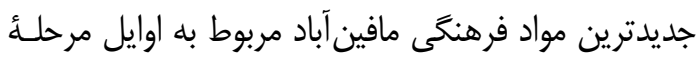

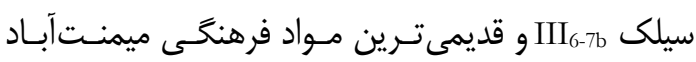

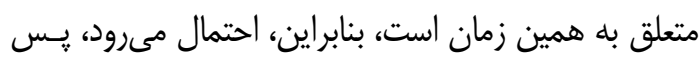

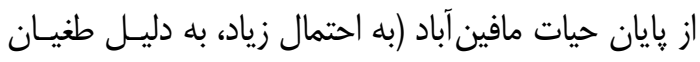
رود باستانى كه شواهد آن در نزديكى محوطه كشف شائ شده

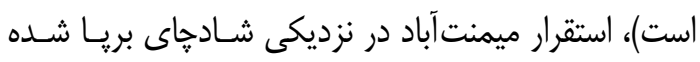

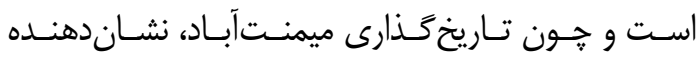

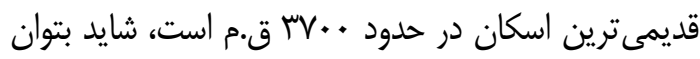

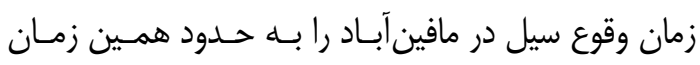

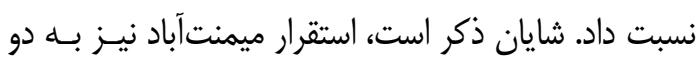

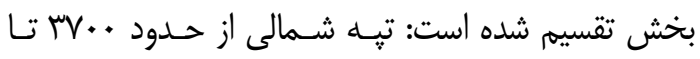

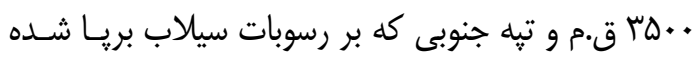

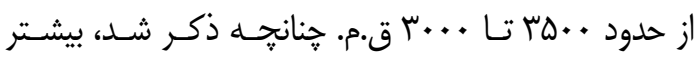
يزوهشهاى ديرين اقليم، وقوع يك دوره تغيير اقليم را در 


\section{References}

[1] Wilhite, D. A. Drought Mitigation Center Faculty Publications; 1992, 64. P. 81-82.

[2] Barry RG, Chorley RJ. Atmosphere, weather and climate. Routledge; 2009 Oct 20.

[3] Wilhite DA, Glantz MH. Understanding: the drought phenomenon: the role of definitions. Water international. 1985 Jan 1;10(3):111-20.

[4] Shaikh Baikloo B. The Impact of Climate Changes of the Mid-Holocene Era on the Cultures of Sixth to Fourth millennium BC in the North of central Iran. Ph.D. in Archeology, Islamic Azad University, Science and Research Branch of Tehran: Faculty of Humanities and Social Sciences; 2017. P. 217. [in Persian]

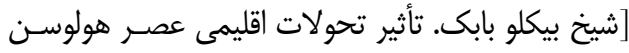

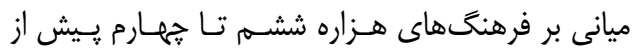

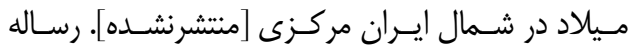

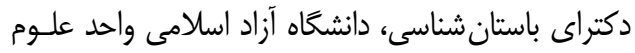

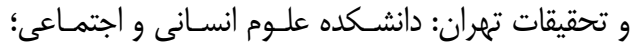

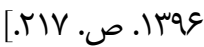

[5] Frenken K. Irrigation in the Middle East region in figures AQUASTAT Survey2008. Water Reports. 2009(34).

[6] Mayewski PA, Rohling EE, Stager JC, Karlén W, Maasch KA, Meeker LD, Meyerson EA, Gasse F, van Kreveld S, Holmgren K, Lee-Thorp J. Holocene climate variability. Quaternary research. 2004 Nov 1;62(3):243-55.

[7] Bond G, Kromer B, Beer J, Muscheler R, Evans MN, Showers W, Hoffmann S, Lotti-Bond R, Hajdas I, Bonani G. Persistent solar influence on North Atlantic climate during the Holocene. Science. 2001 Dec 7;294(5549):2130-6.

[8] Bond G, Showers W, Cheseby M, Lotti R, Almasi P, DeMenocal P, Priore P, Cullen H, Hajdas I, Bonani G. A pervasive millennial-scale cycle in North Atlantic Holocene and glacial climates. science. 1997 Nov 14;278(5341):1257-66.

[9] Alley RB. GISP2 ice core temperature and accumulation data. IGBP PAGES/World Data Center for Paleoclimatology Data Contribution Series. 2004; 13:2004.

[10] Maghsoudi M, Jafarbigloo M, Rahimi O. Sedimentary evidence of climate change in Zeribar Lake during the Holocene.
Natural Geography Research. 2014;46(1): 43-58. [in Persian]

[مقصـودى مهـران، جعفربيگلـو منصــور، رحيمسى اميـد.

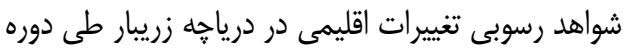

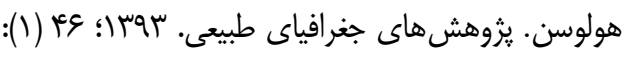

$[. \Delta \Lambda-r)$

[11] Wasylikowa K, Witkowski A, Walanus A, Hutorowicz A, Alexandrowicz SW, Langer JJ. Palaeolimnology of Lake Zeribar, Iran, and its climatic implications. Quaternary Research. 2006 Nov;66(3):477-93.

[12] Stevens LR, Ito E, Schwalb A, Wright HE. Timing of atmospheric precipitation in the Zagros Mountains inferred from a multiproxy record from Lake Mirabad, Iran. Quaternary research. 2006 Nov; 66(3):494500 .

[13] Djamali M, De Beaulieu JL, Miller NF, Andrieu-Ponel V, Ponel P, Lak R, Sadeddin N, Akhani H, Fazeli $H$. Vegetation history of the SE section of the Zagros Mountains during the last five millennia; a pollen record from the Maharlou Lake, Fars Province, Iran. Vegetation History and Archaeobotany. 2009 Mar 1;18(2):123-36.

[14] Lak R. Geological Survey Report of Lake Maharlou, Phase I, Hydrochemistry and Hydrogeochemistry. Tehran: Geological Organization of Iran; 2007. [in Persian]

] لى راضيه. گزارش بررسى زمينشناسى درياجه مهارلو،

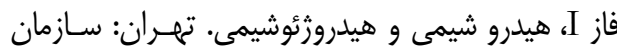

زمينشناسى كشور؛ عرسا.]

[15] Sharifi A, Pourmand A, Canuel EA, FererTyler E, Peterson LC, Aichner B, Feakins SJ, Daryaee T, Djamali M, Beni AN, Lahijani HA. Abrupt climate variability since the last deglaciation based on a highresolution, multi-proxy peat record from NW Iran: The hand that rocked the Cradle of Civilization? Quaternary Science Reviews. 2015 Sep 1;123: 215-30.

[16] Hamzeh MA, Mahmudy Gharaie MH, Alizadeh Lahijani H, Moussavi Harami R, Djamali M. Aeolian sediments deposited in Lake Hamoun; the proxy of frequency and severity of dust storms in Sistan since the late glacial. 2015; 33(1):1-24. [in Persian]

] حمزه محمدعلى، محمودى قرائى محمدحسين، عليزاده

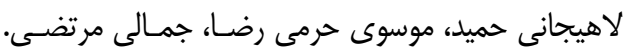


رسوبات بادى نهشـته شـده در درياجـهُ هـامون نشـانغخر

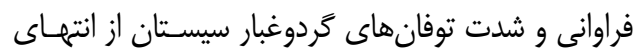

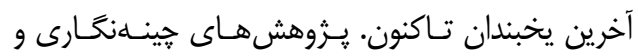

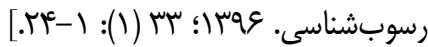

[17] Vaezi A, Ghazban F, Tavakoli V, Routh J, Beni AN, Bianchi TS, Curtis JH, Kylin H. A Late Pleistocene-Holocene multi-proxy record of climate variability in the Jazmurian playa, southeastern Iran. Palaeogeography, palaeoclimatology, palaeoecology. 2019 Jan 15; 514: 754-67.

[18] Ali MO. Palynological evidences on paleoclimate and paleoenvironmental changes during Holocene of Al-Hussaynia District, Central Iraq. Arabian Journal of Geosciences. 2014 Feb 1;7(2):589-95.

[19] Jassim RZ, Al-Rawi YT, Habib HR. Holocene aridification in central Iraq. Iraqi Bulletin of Geology and Mining. 2007;3(1):1-9.

[20] Bar-Matthews M, Ayalon A. MidHolocene climate variations revealed by high-resolution speleothem records from Soreq Cave, Israel and their correlation with cultural changes. The Holocene. 2011 Feb;21(1):163-71.

[21] Cullen HM, Demenocal PB. North Atlantic influence on Tigris-Euphrates streamflow. International journal of climatology. 2000 Jun 30;20(8):853-63.

[22] Chaychi Amirkhiz A. Mafin Abad Tepe. Special issue of Tehran province archeological research conference. Research Institute of Archeology, Tehran Cultural Heritage, Handicrafts and Tourism Organization and Islamic Azad University of Varamin-Pishva Branch. 2007; 37-45 [in Persian].

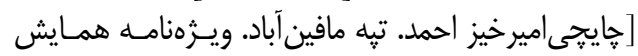

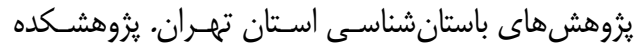

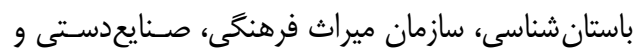

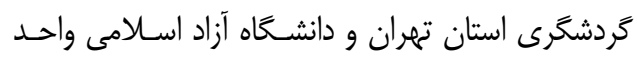

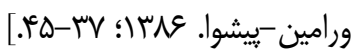

[23] Chaychi Amirkhiz A, Mossadeghi Amini F. Excavation to determine the extent and type of soil and sedimentary environment of Mafin Abad Tepe of Islamshahr. Tehran: Cultural Heritage and Handicrafts and Tourism Organization; 2006. [in Persian]

] جايجى اميرخيز احمد، مصدقى امينى فرشيد. گمانـهزنسى

براى تعيين حريم و تعيين نوع خاك و محيط رسوبى تِّيه

$$
\begin{aligned}
& \text { مافين آباد اسلامشهر. تهران: سازمان ميـراث فرهنخـى و } \\
& \text { صنايع دستى و گردشخرى؛ همسا. [منتشرنشده].] }
\end{aligned}
$$

[24] Kaboli MA. Archaeological Surveys of Qomroud. Tehran: National Heritage Research Institute; 1999. P. 33, 72, 79, 83, 140-142. [in Persian]

[كابلى مير عابدين. بررسىهاى باسـتان شناسـى قمـرود.

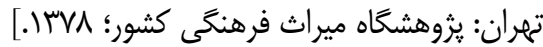

[25] Kaboli MA. Excavations at Ghara Tepe of Qomroud. Tehran: National Heritage Research Institute; 2015. [in Persian]

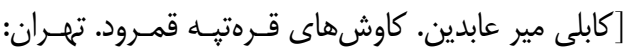

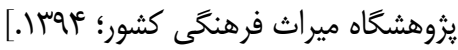

[26] Zoshk RY, Mohammadi KB, Zeighami M, Baghizadeh S, Golcheh M, Ahmadpour H, Miri J, Nezhad MG, Nezari N, Mohammadi NB, Alimadadi E. MeymanatAbad Tepe: An important Site in Late Fourth Millennium BC in Iranian Central Plateau. Archaeology. 2015;4(1):13-21.

[27] Maghsoudi, M., Zamanzadeh, S., navidfar, A., Yosefi Zoshk, R., Ahmadpour, H. Geoarchaeology of Prehistoric Settlements Using Micromorphology Methods (The case study: Meimanatabad Cluster). Journal of Archaeological Studies. 2015;7(2):149-164. [in Persian]

[مقصودى، مهران، زمان زاده، سيد محمد، نويد فر، اصـغر،

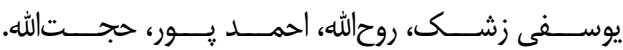

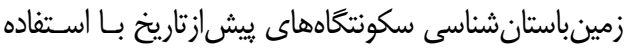

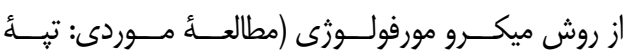

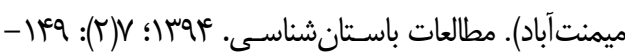

[28] Maghsoudi M, Zamanzadeh S M, Navidfar A, Mohammadi A, Yosefi Zoshk R. Environmental conditions' study governing on ancient sites with an emphasis on grain size sediment river analysis (Case study: Ancient sites of Meymanatabad and Mafinabad). Quaternary Journal of Iran. 2016;2(1):4155. [in Persian]

[مقصودى مهران، زمان زاده سيد محمد، نويد فر اصـغر،

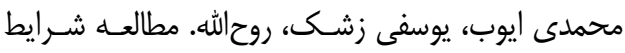

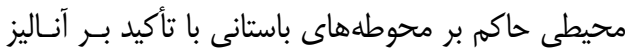

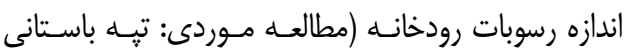

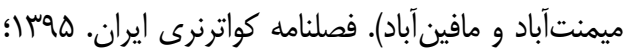
[.

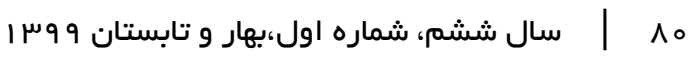

